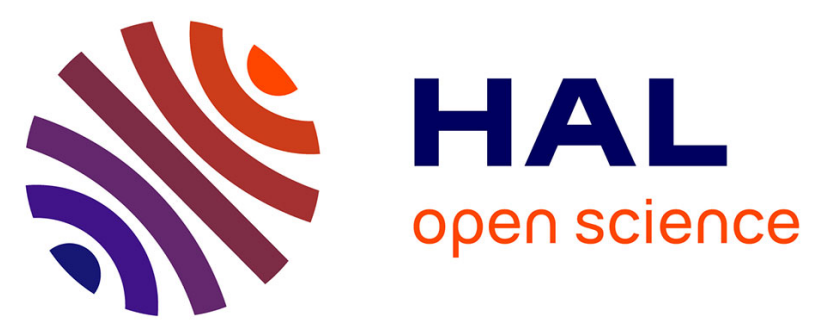

\title{
Evolution of N-Coordinated Iron-Carbon (FeNC) Catalysts and Their Oxygen Reduction (ORR) Performance in Acidic Media at Various Stages of Catalyst Synthesis: An Attempt at Benchmarking
}

Kuldeep Mamtani, Deepika Singh, Juan Tian, J. M. M. Millet, Jeffrey Miller, Anne C Co, Umit S Ozkan

\section{To cite this version:}

Kuldeep Mamtani, Deepika Singh, Juan Tian, J. M. M. Millet, Jeffrey Miller, et al.. Evolution of N-Coordinated Iron-Carbon (FeNC) Catalysts and Their Oxygen Reduction (ORR) Performance in Acidic Media at Various Stages of Catalyst Synthesis: An Attempt at Benchmarking. Catalysis Letters, 2016, 146 (9), pp.1749-1770. 10.1007/s10562-016-1800-z . hal-01382692

\section{HAL Id: hal-01382692 https://hal.science/hal-01382692}

Submitted on 7 Oct 2021

HAL is a multi-disciplinary open access archive for the deposit and dissemination of scientific research documents, whether they are published or not. The documents may come from teaching and research institutions in France or abroad, or from public or private research centers.
L'archive ouverte pluridisciplinaire HAL, est destinée au dépôt et à la diffusion de documents scientifiques de niveau recherche, publiés ou non, émanant des établissements d'enseignement et de recherche français ou étrangers, des laboratoires publics ou privés. 


\title{
Evolution of N-Coordinated Iron-Carbon (FeNC) Catalysts and Their Oxygen Reduction (ORR) Performance in Acidic Media at Various Stages of Catalyst Synthesis: An Attempt at Benchmarking
}

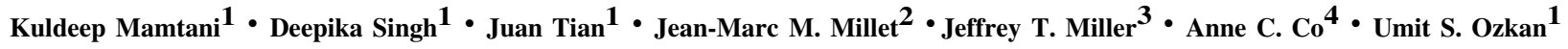 \\ 1 William G. Lowrie Department of Chemical and Biomolecular Engineering, The Ohio State University, Columbus, OH 43202, USA \\ 2 IRCELYON, Institut de Recherche sur la Catalyse et l'Environnement de Lyon, UMR 5256 Universite Claude-Bernard Lyon 1, 2 av. \\ A. Eisntein, 69626 Villeurbanne Cedex, France \\ 3 School of Chemical Engineering, Purdue University, West Lafayette, IN 47907, USA \\ 4 Department of Chemistry and Biochemistry, The Ohio State University, Columbus, OH 43202, USA
}

\begin{abstract}
The objective of this study was to understand the role of iron and the heat treatment steps involved in nitrogen-coordinated iron-carbon (FeNC) catalyst synthesis. We have studied the oxygen reduction reaction (ORR) performance of these catalysts as they evolve from their most crude and inactive form to their most active form. Electrochemical half-cell and fuel cell tests suggest that the presence of Fe was crucial in these samples. The hightemperature heat treatment (once in argon and then in ammonia) at temperatures $\geq 950{ }^{\circ} \mathrm{C}$ were also critical in imparting these catalysts with their highest activity; however, significant loss of activity was observed with cycling and potential hold at $0.5 \mathrm{~V}$ for $100 \mathrm{~h}$. In addition, acidwashing after the first or the second pyrolysis steps produced a marked decrease in ORR activity relative to their unwashed counterparts. We also report findings from our efforts towards benchmarking FeNC catalysts for oxygen reduction reaction electrocatalysis. Specifically, we focus on correlating the specific kinetic current $\left(\mathrm{i}_{\mathrm{K}}\right)$ at $0.75 \mathrm{~V}$ to electrochemically accessible surface area (EASA) and roughness factor (RF) determined from electrochemical double layer capacitance measurements. ${ }^{57} \mathrm{Fe}$ Mössbauer spectroscopy was employed to shed light into the nature of active sites in FeNC catalysts and provide insights into their deactivation behavior caused by acid-washing. The results suggest planar $\mathrm{FeN}_{4}$ doublet $\left(\mathrm{Fe}^{2+}\right.$, low spin) as an active site in these materials, which may be leached away in acid, explaining their decreased activity after acid washing. Results for characterization experiments using $\mathrm{X}$-ray photoelectron spectroscopy, temperature programmed oxidation and X-ray absorption spectroscopy, superconducting quantum interference device magnetometry are also presented.
\end{abstract}

Keywords FeNC · ORR - Oxygen reduction reaction . Mössbauer spectroscopy $\cdot$ Planar $\mathrm{FeN}_{4}$

\section{Introduction}

Increasing energy demands and environmental concerns make the development of technologies which are clean, efficient and environmentally friendly more important than ever. Hydrogen-based proton exchange membrane (PEM) fuel cells provide one such alternative. The low temperature of PEM fuel cells $\left(\sim 85^{\circ} \mathrm{C}\right)$ and the slow kinetics of oxygen reduction reaction (ORR) at the cathode necessitate higher loadings of platinum-based catalysts. Platinumbased catalysts are expensive, available in limited reserves and are susceptible to poisons such as $\mathrm{CO}$ and $\mathrm{H}_{2} \mathrm{~S}$ in the fuel. Therefore, research towards development of nonnoble metal-based cathode (NNMC) catalysts is necessary.

NNMCs have, in fact, been studied for the last five decades. It was Jasinski [1] who first observed ORR activity of cobalt macrocycles. Later, it was reported that heat-treatment under an inert atmosphere such as $\mathrm{N}_{2}$ or $\mathrm{Ar}$ at temperatures higher than $400{ }^{\circ} \mathrm{C}$ leads to an enhancement of not only the activity, but also the stability [2]. It was Yeager and co-workers who first developed active and stable ORR catalysts by impregnating the carbon support with transition metal salts and polyacrylonitrile (PAN) and pyrolizing it in argon at $800{ }^{\circ} \mathrm{C}$ [3]. Their study was significant in highlighting that transition metal and nitrogen can come from different sources, thereby allowing use of simpler and cheaper molecules instead of expensive macrocycles.

The understanding that macrocycles can be replaced with simpler molecules paved the way for new materials as ORR catalysts. Dodelet and co-workers have pioneered the development of iron-nitrogen-carbon (FeNC) catalysts [4-17]. They have proposed co-existence of two types of catalytic sites namely $\mathrm{FeN}_{4} / \mathrm{C}$ and $\mathrm{FeN}_{2} / \mathrm{C}$ based on timeof-flight secondary ion mass spectrometry [5]. One of their most notable works employed ball-milling a mixture of iron (II) acetate, phenanthroline and a carbon support and pyrolizing it first in argon and then in ammonia. They 
reported activities of these FeNC catalysts to be comparable to that of platinum in the fuel cell tests [12]. Later, they substituted the carbon support with a metal-organic framework ZIF-8 (Zn(II) zeolitic imidazolate framework) and noted a further increase in the ORR performance of these FeNC catalysts [14]. They also employed Mössbauer spectroscopy to propose the nature of active sites in FeNC catalysts $[15,18]$. Their most recent publication reports addition of $150 \mathrm{~nm}$ carbon fibers in the catalyst mix comprising of phenanthroline, iron (II) acetate and ZIF-8 to further increase the ORR performance of their catalysts [16].

The nature of active sites in NNMCs has been widely debated in the electro-catalysis community. In addition to reports where metal is proposed to be an integral part of the active site, there are other works which suggest that the role of transition metal is merely to catalyze the growth of carbon nanostructures and facilitate the incorporation of nitrogen functionalities on the carbon surface. The activity of nitrogen-doped carbon nanostructures $\left(\mathrm{CN}_{\mathrm{x}}\right)$ as ORR catalysts in acidic medium was first reported in our early work [19-22]. $\mathrm{CN}_{\mathrm{x}}$ catalysts prepared by pyrolyzing a carbon and nitrogen source over a supported metal growth substrate clearly showed metal to be encased within the carbon nanostructure after the acid-washing step through Transmission Electron Microscopy (TEM), X-ray photoelectron spectroscopy and Mössbauer spectroscopy. We have also noted significant ORR activity for carbon nanostructures grown over pure alumina providing further evidence to the hypothesis that ORR activity of these materials can be achieved without the presence of a metal. The metal-free active site assertion in $\mathrm{CN}_{\mathrm{x}}$ catalysts was also validated using well-known poisons such as $\mathrm{CO}$ and $\mathrm{CN}^{-}$as probe molecules [23]. Later studies supported these findings [24-29] including the significant ORR activity of $\mathrm{N}$-doped graphene reported by Dai et al.

We have recently provided more evidence that FeNC and $\mathrm{CN}_{\mathrm{x}}$ catalysts are in fact fundamentally different materials and have very different active sites for ORR in acidic media. Acid-washing was shown to leach out $\mathrm{Fe}$ from Fe-based sites in FeNC catalysts, thus decreasing the activity, whereas it had just the opposite effect for $\mathrm{CN}_{\mathrm{x}}$ catalysts with the role of acid-washing being to remove the inactive metallic particles blocking the active sites and the non-conductive oxide support [30]. In addition, a marked decrease in activity was noted for FeNC catalysts after $\mathrm{H}_{2} \mathrm{~S}$ treatment providing evidence that iron is an essential part of the ORR active site in these catalysts [31] unlike $\mathrm{CN}_{\mathrm{x}}$ catalysts where no decrease in activity was observed after sulfur exposure [32].

Some ground-breaking research led by Dodelet and coworkers, as pointed out earlier, places FeNC catalysts amongst the most active non-noble metal-based ORR electrocatalysts to date. However, there is limited information available on the evolution of these materials on ORR performance through the various synthesis stages. Furthermore, the effect of acid-washing (if used as a probe) on these materials is not clearly demonstrated. In-addition, there is no consistency in the way the catalysts are compared for their ORR performance in the literature. The difficulty arises from the fact that there are no set procedures or protocols unlike for Pt-based systems. Limited and contradictory information on the actual ORR active sites in NNMCs increases the challenge further. This calls for extensive research efforts towards benchmarking nonnoble metal based ORR electrocatalysts which have been neglected previously except in few studies [33].

With this motivation, we conducted a study examining these NNMCs from their precursor (inactive) form to their most active form. The first part of the study aims to investigate the effect of iron on the ORR performance. This was achieved by synthesizing "comparative" samples with no addition of iron. The role of the heat treatment step in an inert and a reactive environment was also studied. The second part of the study sheds light into the deactivation behavior of these catalysts caused by acid-washing. It should be noted that acid-washing is being used merely as a probe to gain insights into the actual ORR active sites in these materials.

Finally, this work attempts to benchmark the activity of NNM ORR catalysts. In particular, the focus was to correlate ORR activity with electrochemically accessible surface area (EASA) and the roughness factor (RF) using double layer capacitance measurements and ${ }^{57} \mathrm{Fe}$ Mössbauer Spectroscopy.

Several surface and bulk characterization techniques namely X-ray Photoelectron Spectroscopy (XPS), Temperature programmed oxidation (TPO), X-ray Absorption Spectroscopy (XAS) and ${ }^{57} \mathrm{Fe}$ Mössbauer Spectroscopy and Superconducting Quantum Interference Device (SQUID) magnetometry were used for characterization while activity measurements were done by using half-cell and fuel cell tests.

\section{Experimental}

\subsection{Catalyst Synthesis}

$\mathrm{N}$-coordinated iron-carbon (FeNC) catalyst synthesis was performed following the procedure described by Lefevre et al. [12]. Briefly, $500 \mathrm{mg}$ of phenanthroline dissolved in a 1:2 ratio by volume of ethanol: water was mixed with $31.2 \mathrm{mg}$ of iron (II) acetate. When a deep red color, indicative of the formation of $\left[\mathrm{Fe}(\text { phen })_{3}\right]^{2+}$ complex was observed, $500 \mathrm{mg}$ of Black Pearls 2000 was added to 
obtain a nominal $\mathrm{Fe}$ loading of $1 \%$. This mixture was stirred in a water bath at $70{ }^{\circ} \mathrm{C}$ until the solution volume was reduced to one third of the original volume and then kept overnight in the oven. The resulting material was then ball-milled at $200 \mathrm{rpm}$ for $3 \mathrm{~h}$ using a rotary ball-mill. The ball-milled precursor underwent through two pyrolysis steps, first in argon at $1050{ }^{\circ} \mathrm{C}$ for $1 \mathrm{~h}$ and then in ammonia at $950{ }^{\circ} \mathrm{C}$ for $20 \mathrm{~min}$. On one set of samples, an acidwashing step at $60{ }^{\circ} \mathrm{C}$ in $1 \mathrm{M} \mathrm{HCl}$ was also employed after each heat-treatment to study the effect of acid-washing on the ORR activity of these catalysts. Another set of samples was also synthesized without adding iron (II) acetate and keeping all the other synthesis steps same as before. Acidwashing was not performed for samples containing no iron. Nomenclature for various samples used in this study is shown in Table 1 .

\subsection{Half-Cell Testing}

The oxygen reduction reaction (ORR) activity was performed in a standard three-electrode system, comprising of a working electrode (glassy carbon disk, $0.196 \mathrm{~cm}^{2}$ ), a reference electrode $(\mathrm{Ag} / \mathrm{AgCl}$ (sat. $\mathrm{KCl})$ ) and a counter electrode ( $\mathrm{Pt}$ coil) in $0.5 \mathrm{M} \mathrm{H}_{2} \mathrm{SO}_{4}$ and measured using a Bio-Logic potentiostat. To prepare the catalyst ink, a $95 \mu \mathrm{L}$ of $5 \mathrm{wt} \%$ Nafion solution and $350 \mu \mathrm{L}$ of ethanol were added to $10 \mathrm{mg}$ of catalyst weighed in a $2 \mathrm{~mL}$ vial. The solution was sonicated in an ice bath until the catalyst was well-dispersed, at which time a $7 \mu \mathrm{L}$ of the catalyst ink was pipetted onto the glassy carbon disk resulting in a catalyst loading of $800 \pm 10 \mu \mathrm{g} / \mathrm{cm}^{2}$. To measure the catalyst activity, cyclic voltammograms (CVs) were collected starting from 1.2 to 0 to $1.2 \mathrm{~V} \mathrm{vs}$. NHE at $10 \mathrm{mV} / \mathrm{s}$ in an oxygen saturated solution with the working electrode rotating at 400, 800, 1000, 1200 and $1600 \mathrm{rpm}$. CVs were also collected in an argon-saturated electrolyte at corresponding sweep rate and rotation rates, serving as blank spectra. Data reported herein are ORR data resulting from the subtraction of the ORR CV from the blank $\mathrm{CV}$, where the capacitive contribution was removed from the Faradaic current reported.

ORR activity in this work are evaluated by comparing (i) potential at a background subtracted current density of $-0.1 \mathrm{~mA} / \mathrm{cm}^{2}$, (ii) half-wave potential $\left(\mathrm{E}_{1 / 2}\right)$, (iii) specific kinetic current $\left(i_{K}\right)$ at $0.75 \mathrm{~V}$, (iv) rate constant $(k)$ for ORR at equilibrium. Calculation of $i_{K}, k$ and the number of electrons transferred per molecule of oxygen $(n)$ was made using the Koutechy-Levich relationship (Eq. 1).

$\frac{1}{i}=\frac{1}{i_{K}}+\frac{1}{i_{\text {lim }}}$

where $i$ is the measured current density, $i_{K}$ is kinetic current density defined by $i_{K}=n F k C_{O_{2}} i_{K}=n F k C_{O_{2}}$ and $i_{\text {lim }}$ is the limiting current density which can be described by $i_{\text {lim }}=0.62 n F D^{2 / 3} C_{O_{2}} \vartheta^{-\frac{1}{6}}$ Here, $F$ is the Faraday's constant ( $96485 \mathrm{C} /$ mole of electrons), $k$ is the rate constant for ORR, $\mathrm{CO}_{2}$ is the bulk concentration of oxygen $\left(1.26 \times 10^{-6}\right.$ $\left.\mathrm{mol} / \mathrm{cm}^{3}\right)[34,35], D$ is the diffusion coefficient of oxygen $\left(1.93 \times 10^{-5} \mathrm{~cm}^{2} / \mathrm{s}\right)[34,35]$ in $0.5 \mathrm{M} \mathrm{H}_{2} \mathrm{SO}_{4}, \vartheta$ is the kinematic viscosity of the electrolyte $\left(1.009 \times 10^{-2} \mathrm{~cm}^{2} / \mathrm{s}\right)$ [34, 35].

All potentials referred in this work are measured with $\mathrm{Ag} / \mathrm{AgCl}(\mathrm{KCl}$ sat) reference electrode and reported with

Table 1 Nomenclature of samples used in this study

\begin{tabular}{|c|c|c|c|c|c|c|}
\hline $\begin{array}{l}\text { Nomenclature } \\
\text { used }\end{array}$ & $\mathrm{Fe}$ & $\begin{array}{l}\mathrm{N} \text { in the starting } \\
\text { synthesis mixture }\end{array}$ & $\begin{array}{l}\text { 1st heat treatment ( } \mathrm{Ar} \\
\left.1050^{\circ} \mathrm{C}, 60 \mathrm{~min}\right)\end{array}$ & $\begin{array}{l}\text { Acid-wash after 1st } \\
\text { heat treatment }\end{array}$ & $\begin{array}{l}\text { 2nd heat treatment }\left(\mathrm{NH}_{3}\right. \\
\left.950^{\circ} \mathrm{C}, 20 \mathrm{~min}\right)\end{array}$ & $\begin{array}{l}\text { Acid-wash after } 2 \text { nd } \\
\text { heat treatment }\end{array}$ \\
\hline $\mathrm{BP}-\mathrm{Ar}$ & $x$ & $x$ & $\boldsymbol{v}$ & $x$ & $x$ & $x$ \\
\hline BP-Ar-NH 3 & $x$ & $x$ & $\boldsymbol{v}$ & $x$ & $\checkmark$ & $x$ \\
\hline BP-Ph & $x$ & $\checkmark$ & $x$ & $x$ & $x$ & $x$ \\
\hline BP-Ph-Ar & $x$ & $\checkmark$ & $\boldsymbol{v}$ & $x$ & $x$ & $x$ \\
\hline BP-Ph-Ar-NH ${ }_{3}$ & $x$ & $v$ & $\boldsymbol{v}$ & $x$ & $\boldsymbol{v}$ & $x$ \\
\hline BP-Ph-Fe & $\boldsymbol{v}$ & $v$ & $x$ & $x$ & $x$ & $x$ \\
\hline BP-Ph-Fe-Ar & $\boldsymbol{v}$ & $v$ & $\boldsymbol{v}$ & $x$ & $x$ & $x$ \\
\hline $\begin{array}{l}\text { BP-Ph-Fe-Ar- } \\
\mathrm{NH}_{3}\end{array}$ & $\checkmark$ & $v$ & $\boldsymbol{V}$ & $x$ & $v$ & $x$ \\
\hline $\begin{array}{l}\text { BP-Ph-Fe-Ar- } \\
\text { washed }\end{array}$ & $\boldsymbol{v}$ & $\checkmark$ & $\boldsymbol{v}$ & $\boldsymbol{v}$ & $x$ & $x$ \\
\hline $\begin{array}{l}\text { BP-Ph-Fe-Ar- } \\
\mathrm{NH}_{3} \text {-washed }\end{array}$ & $\boldsymbol{v}$ & $\checkmark$ & $\boldsymbol{v}$ & $x$ & $\checkmark$ & $\checkmark$ \\
\hline
\end{tabular}

$\boldsymbol{V}$ indicates presence of iron or nitrogen in the starting mixture or that of a particular treatment

$\boldsymbol{X}$ indicates absence of iron or nitrogen in the starting mixture or that of a particular treatment 
respect to a normal hydrogen electrode (NHE). The measurement of the selectivity towards water formation was also performed for select samples using a rotating ring disk electrode (RRDE). All experimental conditions were the same as noted above except for the working electrode, which consisted of a glassy carbon disk $\left(0.2472 \mathrm{~cm}^{2}\right)$ surrounded by a Pt ring. The Pt-ring was held at a constant potential of $1.2 \mathrm{~V}$ while scanning the disk and calculation of the selectivity was done using Eq. (2). A selectivity of four corresponds to a complete reduction of oxygen to water, whereas that of two is equivalent to $100 \%$ formation of hydrogen peroxide.

$n=\frac{4 I_{D}}{I_{D}+\frac{I_{R}}{N}}$

where $n$ is the number of electrons transferred per oxygen molecule, $I_{D}$ is disk current, $I_{R}$ is the ring current and $N$ is the collection efficiency $(37 \%$ as specified by the manufacturer).

Accelerated durability tests (ADTs) were performed by first collecting initial activity data as mentioned above. The electrode was then cycled from $1.2 \mathrm{~V}$ to $0 \mathrm{~V}$ to $1.2 \mathrm{~V}$ vs. $\mathrm{NHE}$ at $100 \mathrm{mV} / \mathrm{s}$ in an oxygen saturated electrolyte. The electrode was held at $1.2 \mathrm{~V}$ for $5 \mathrm{~s}$ after each cycle. Activity data was collected after 1000 cycles.

EASAvalues reported in this study were obtained by measuring electrical double layer capacitance $\left(\mathrm{C}_{\mathrm{dl}}\right)$ between 1.2 and $1 \mathrm{~V}$ vs. NHE CVs were collected in argon saturated electrolyte at various scan rates by scanning the potential across the non-Faradaic region. The current in this potential window is attributed entirely due to double-layer charging and is denoted as $\mathrm{I}_{\text {capacitive. The double-layer }}$ charging current ( $\mathrm{I}_{\text {capacitive }}$ ) is proportional to the scan rate (v) as shown by Eq. (3).

$I_{\text {capacitive }}=C_{d l} v$

Thus, the slope of $I_{\text {capacitive }}$ vs. $v$ plot corresponds to $C_{d l}$.

EASA defined in Eq. 4 was then obtained using the estimated $\mathrm{C}_{\mathrm{dl}}$ values. For our calculations, we have used a specific capacitance $\left(C_{\mathrm{s}}\right)$ value of $20 \mu \mathrm{F} / \mathrm{cm}^{2}$ based on literature [36-41].

$E A S A=\frac{C_{d l}}{C_{S}}$

Roughness factor (RF) was calculated as the ratio of EASA on the electrode to the geometric area of the disk electrode.

\subsection{Fuel Cell Testing}

Membrane Electrode Assemblies (MEAs) were prepared by the following method. Anode comprised of commercial $20 \mathrm{wt} \% \mathrm{Pt} / \mathrm{C}$ (Pt loading $0.5 \mathrm{mg} / \mathrm{cm}^{2}$ ) from Fuel Cells Etc.
The ink for the cathode catalyst was prepared by adding $326 \mu \mathrm{L}$ of $5 \mathrm{wt} \%$ Nafion solution, $163 \mu \mathrm{L}$ of ethanol (200 proof) and $136 \mu \mathrm{L}$ of deionized water to a vial containing $10 \mathrm{mg}$ of the catalyst sample. The vial was later sonicated in an ice bath until the catalyst was well-dispersed. $71 \mu \mathrm{L}$ of the ink was then pipetted onto a gas diffusion layer of carbon paper $\left(1.14 \mathrm{~cm}^{2}\right)$, which corresponds to a catalyst loading of $1 \mathrm{mg} / \mathrm{cm}^{2}$. After drying, the electrodes were hotpressed at $140{ }^{\circ} \mathrm{C}$ with a Nafion 115 membrane in between them.

Fuel cell tests were performed using an Arbin Fuel Cell Test Stand. The hydrogen and the oxygen were leak tested and were then pressurized using nitrogen. When desired pressures were attained, flows were switched to hydrogen and oxygen. Typically, tests were performed using a cell temperature of $80{ }^{\circ} \mathrm{C}$, flow rates of $\mathrm{O}_{2}$ and $\mathrm{H}_{2}$ of $300 \mathrm{~cm}^{3}$ / min with a back-pressure of 15 psig. Polarization curves were obtained by scanning the cell potential from open circuit voltage $(\mathrm{OCV})$ to $0 \mathrm{~V}$ at a scan rate of $0.5 \mathrm{mV} / \mathrm{s}$. For stability tests, the first polarization curve was recorded once the temperature and pressures reached steady-state. The cell was then held at a potential of $0.5 \mathrm{~V}$ for $1 \mathrm{~h}$, before recording another polarization curve. The cell was then held at $0.5 \mathrm{~V}$ for $100 \mathrm{~h}$ before recording the third polarization curve.

\subsection{X-ray Photoelectron Spectroscopy (XPS)}

XPS was used to analyze the composition of the surface species present on various catalysts. A Kratos Ultra Axis spectrometer was used with a monochromatic aluminum anode source operated at $12 \mathrm{kV}$ and $10 \mathrm{~mA}$. Binding energies were referenced to the standard $\mathrm{C} 1 \mathrm{~s}$ binding energy of $284.5 \mathrm{eV}$. XPSpeak 4.1 software package was used for curve fitting. Spectra baselines were determined using Shirley-type background fitting. Spectra were deconvoluted using Lorentzian-Gaussian combination peaks.

\subsection{Temperature Programmed Oxidation (TPO)}

TPOexperiments were performed using an Autochem 2010 under $10 \% \mathrm{O}_{2} / \mathrm{He}$ gas flowing at $30 \mathrm{~cm}^{3} / \mathrm{min}$. Typically, $30 \mathrm{mg}$ of the catalyst sample was packed in a U-tube quartz reactor and held in a high-temperature furnace. The sample temperature was first allowed to equilibrate to $50{ }^{\circ} \mathrm{C}$ for $15 \mathrm{~min}$, and then the temperature was ramped to $850^{\circ} \mathrm{C}$ at $5{ }^{\circ} \mathrm{C} / \mathrm{min}$ and held there for $20 \mathrm{~min}$. The TPO product stream was fed to an MKS Cirrus benchtop residual gas analyzer with mass signals of 1-100 monitored throughout the experiment. 


\subsection{X-ray Absorption Spectroscopy (XAS)}

Spectra were collected for the Fe K-edge $(7112 \mathrm{eV})$ at the bending magnet beamline (5BM-D) of the Dow-Northwestern-DuPont Collaborative Access Team (DND-CAT) of the Advanced Photon Source, Argonne National Laboratory. The measurements were made in transmission mode with the $\mathrm{Si}$ (111) monochromator detuned by $30 \%$ to eliminate the higher order harmonics in the beam. The samples were pelletized using a die of diameter $13 \mathrm{~mm}$ and held in a 6 sample-holder against Kapton tapes transparent to the X-ray beam. Spectra for all samples and standards were collected in the ex situ mode.

\section{$2.7{ }^{57} \mathrm{Fe}$ Mössbauer Spectroscopy}

${ }^{57} \mathrm{Fe}$ Mössbauer experiments were carried out using a constant accelerator spectrometer in transmission mode. ${ }^{57} \mathrm{Co} / \mathrm{Rh}$ matrix $(10 \mathrm{mCi})$ was used as the Mössbauer source. All measurements were performed at room temperature using $\alpha$ $\mathrm{Fe}$ as the calibration reference and in the velocity range of $\pm 5 \mathrm{~mm} / \mathrm{s}$. Experimental data was fitted using Kaleida Graph assuming Lorentzian shape for all iron sites. The quality of the fit was determined by the classical $\chi^{2}$ test.

\subsection{Superconducting Quantum Conducting Device (SQUID) Magnetometry}

Magnetization was measured as a function of field using a SQUIDmagnetometer (Quantum Design MPMS XL) at $300 \mathrm{~K}$. The applied field was varied from -30000 Oe to +30000 Oe and then back to -30000 Oe. A total of 100 data points were collected for each sample. The data were then fitted to the Langevin function (Eq. 5) and the values for saturation magnetization were determined.

$\frac{M}{M_{\text {sat }}}=L\left(\frac{M_{s} V H}{k_{B} T}\right)$

where $M$ is the magnetization (emu/g), $M_{\text {sat }}$ is the saturation magnetization $(\mathrm{emu} / \mathrm{g}), M_{s}$ is the spontaneous magnetization $\left(\mathrm{emu} / \mathrm{cm}^{3}\right), V$ is the volume of particle $\left(\mathrm{cm}^{3}\right), H$ is the applied field (Oe), $K_{b}$ is the Boltzmann Constant $\left(\mathrm{cm}^{2} \mathrm{gs}^{-2} \mathrm{~K}^{-1}\right), T$ is the temperature $(\mathrm{K})$

$L(x)=\operatorname{coth}(x)-\frac{1}{x}$

is the Langevin function for superparamagnetic particles.

\subsection{Methodology Used for Site Density (SD) and Turnover Frequency (TOF) Calculations}

Site density (SD) and turnover frequency (TOF) values reported here were calculated using the data from Mössbauer spectroscopy and electrochemical half-cell testing.
The amount of $\mathrm{Fe}$, and in turn, the number of $\mathrm{Fe}$ atoms corresponding to each site identified by Mössbauer spectroscopy was calculated and used in determining the site density for a given sample. The specific kinetic current $\left(\mathrm{i}_{\mathrm{K}}\right)$ at $0.75 \mathrm{~V}$ was plotted against site density of each site to identify iron species that contribute to the catalytic activity. Turnover frequency (TOF) values at $0.75 \mathrm{~V}$ were determined using the relation between SD, TOF and volumetric activity $\left(\mathrm{j}_{\mathrm{v}}\right)$ defined by Eq. (6).

$\mathrm{j}_{\mathrm{v}}(0.75 \mathrm{~V})=\mathrm{SD} \times \mathrm{TOF}(0.75 \mathrm{~V}) \times \mathrm{e}$

where, e is the electronic charge $\left(1.6 \times 10^{-19} \mathrm{C}\right)$

TOF values at $0.8 \mathrm{~V}$ (more relevant from an application point of view) were subsequently obtained by extrapolation using Eq. (7).

TOF $(0.8 V)=$ TOF $(0.75 \mathrm{~V}) \times 10^{-50 / \text { Tafel slope }}$

where the value for Tafel slope used was between 0.8 and $0.75 \mathrm{~V}$ vs. NHE.

\section{Results and Discussion}

\subsection{Evolution of FeNC Catalysts Through Preparation Stages}

\subsubsection{Half-Cell and Fuel Cell Testing}

The ORR activities of catalysts with or without iron and with different heat-treatments were measured. Listed in Table 1 are the nomenclature used to describe the catalyst material at each stage of preparation. Figure 1a presents results for samples synthesized with no iron addition. The ORR activities of BP-Ar and BP-Ar- $\mathrm{NH}_{3}$ samples were much lower compared to those for BP-Ph-Ar and BP-PhAr- $\mathrm{NH}_{3}$ samples as evident from their onset potential values presented in Table 2. This observation highlights the positive effect of a nitrogen source (phenanthroline) in the starting synthesis mixture on the activity. In both cases, samples that underwent the second pyrolysis in ammonia were more active and exhibited higher onset potentials than the ones that were heat-treated only in argon (Table 2).

The ORR activities of samples synthesized with iron are compared in Fig. 1b. Samples that were heat-treated (BP$\mathrm{Ph}-\mathrm{Fe}-\mathrm{Ar}$ and $\mathrm{BP}-\mathrm{Ph}-\mathrm{Fe}-\mathrm{Ar}-\mathrm{NH}_{3}$ ) were much more active compared to $\mathrm{BP}-\mathrm{Ph}-\mathrm{Fe}$ which underwent no heat-treatment. Comparison of onset potentials for BP-Ph-Fe-Ar and BP-PhFe-Ar- $\mathrm{NH}_{3}$ (Table 2) suggests that the second pyrolysis in ammonia has a beneficial effect on activity even when iron is present in the sample. The half-wave potential $\left(\mathrm{E}_{1 / 2}\right)$ for the latter was also relatively higher than that for the former $(0.72$ vs. $0.67 \mathrm{~V})$. This can be attributed to incorporation of additional nitrogen functionalities on the catalyst surface 

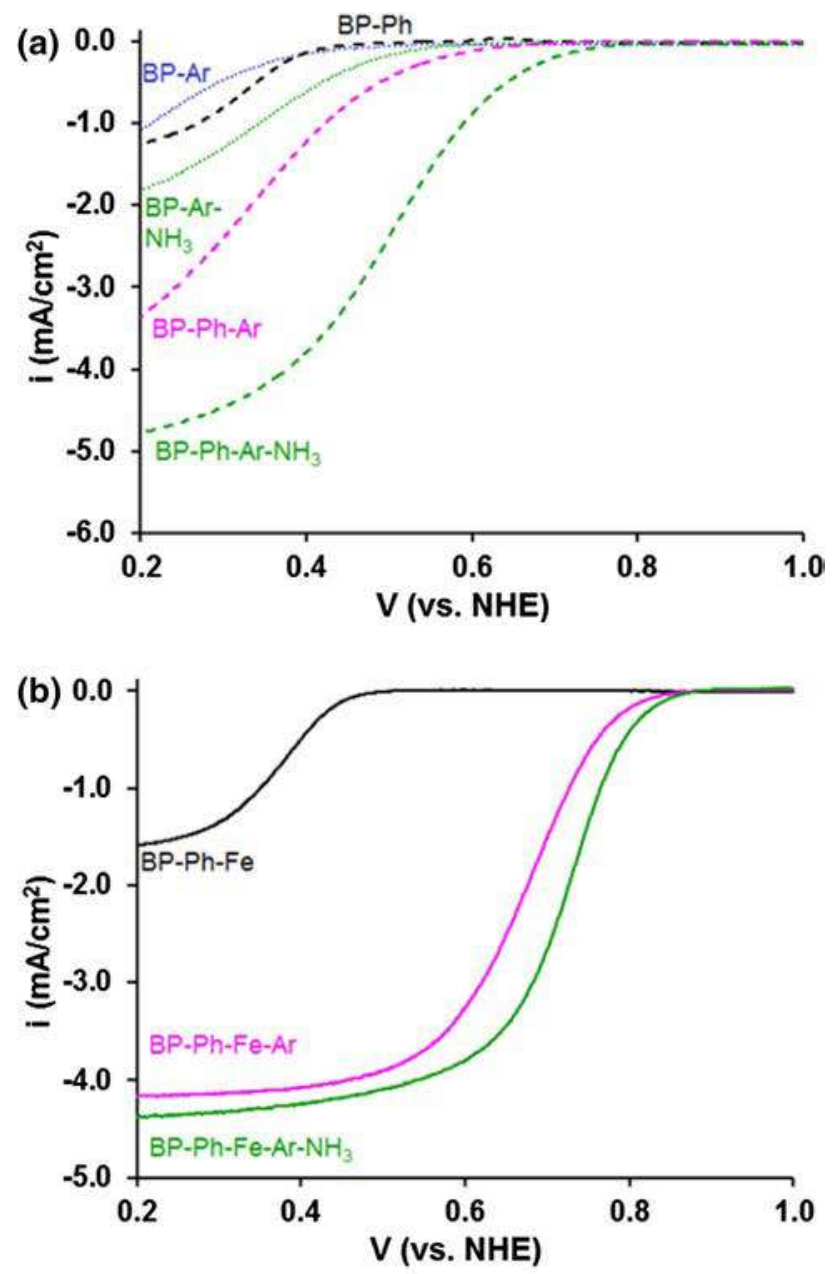

(c)

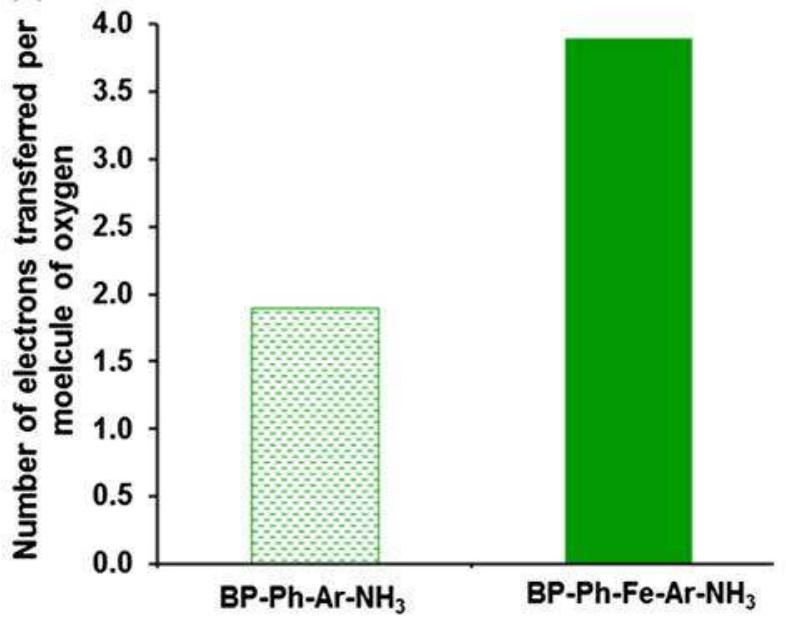

Fig. 1 a ORR activity measurements by RDE at $1000 \mathrm{rpm}$ in $0.5 \mathrm{M}$ $\mathrm{H}_{2} \mathrm{SO}_{4}$ for samples synthesized a without iron addition and b with iron addition. $\mathbf{c}$ Selectivity towards water formation at $0.5 \mathrm{~V}$ vs. NHE for representative samples synthesized with and without iton addition. resulting from the ammonia treatment. It is also clear from Table 2 that the samples containing iron and heat-treated (with $\mathrm{Ar}$ or Ar followed by $\mathrm{NH}_{3}$ ) were much more active than the ones heat-treated, but did not contain iron. The presence of iron was also observed to facilitate ORR to proceed through a four-electron reduction whereas samples with no iron catalyzed ORR through a two electron pathway (Fig. 1c).

Accelerated Durability Tests (ADTs) were performed to determine durability of the two most active samples namely BP-Ph-Fe-Ar and BP-Ph-Fe-Ar- $-\mathrm{NH}_{3}$. This was accomplished by cycling the catalyst between $1.2 \mathrm{~V}$ to $0 \mathrm{~V}$ at a fast rate in an oxygen saturated electrolyte. Results are presented in Fig. 2. BP-Ph-Fe-Ar- $\mathrm{NH}_{3}$ sample exhibited higher initial activity than BP-Ph-Fe- $\mathrm{Ar}$ as also noted previously. However, significant activity losses were observed after 1000 cycles. These activity losses can be ascribed to either the dissolution of iron in the acidic medium or the corrosion of the Black Pearls 2000 support used in the synthesis [42].

Stability of these two catalysts was also determined using a Fuel Cell Test Stand (FCTS). As seen in Fig. 3, BP-Ph-FeAr- $\mathrm{NH}_{3}$ has a higher initial activity than BP-Ph-Fe-Ar in agreement with half-cell tests but after a $100 \mathrm{~h}$ potential hold at $0.5 \mathrm{~V}$, the final activity of both the catalysts is similar. This indicates that sample treated in ammonia (BP-Ph-Fe-Ar$\mathrm{NH}_{3}$ ) exhibited higher loss of activity relative to the one heattreated only in argon (BP-Ph-Fe-Ar). Though the exact mechanism of degradation is not entirely clear, two explanations for loss of activity have been provided. Popov and co-workers [43] have proposed that the pyridinic-N species (believed to be an active site according to one school of thought in ORR literature [19, 43-49]) are protonated to inactive pyridinic-NH species due to the acidic environment of a PEMFC. Dodelet and collaborators have demonstrated that the $\mathrm{N}$ groups on the surface next to the $\mathrm{FeN}_{4}$ active sites undergo protonation to form $\mathrm{NH}^{+}$species which get bound to anions such as sulfonate group of the proton exchange membrane (in case of PEMFC) or bisulfate ions (in case of acid-washing or half-cell experiments) [13]. Considering the fact that these samples have significant amounts of pyridinic$\mathrm{N}$ species (as validated by XPS results presented later in the manuscript) and that $\mathrm{FeN}_{4}$ is the most commonly proposed active site in these materials (and also found in this work and discussed later) both degradation mechanisms are possible.

\subsubsection{X-ray Photoelectron Spectroscopy (XPS)}

XPS spectra for various iron-free samples that are heat treated are shown in Fig. 4. The distribution of various 
Table 2 Onset potentials and half-wave potentials for various samples used in this study

\begin{tabular}{lll}
\hline Sample & Onset potential $\left(\mathrm{V}\right.$ vs. NHE @-0.1 mA/cm $\left.{ }^{2}\right)$ & Half-wave potential $^{*}\left(\mathrm{E}_{1 / 2}\right)(\mathrm{V}$ vs. NHE) \\
\hline BP-Ar & 0.41 & - \\
BP-Ar-NH & - \\
BP-Ph & 0.53 & - \\
BP-Ph-Ar & 0.41 & - \\
BP-Ph-Ar-NH & 0.61 & - \\
BP-Ph-Fe & 0.73 & 0.37 \\
BP-Ph-Fe-Ar & 0.45 & 0.67 \\
BP-Ph-Fe-Ar-NH & 0.82 & 0.72 \\
\hline
\end{tabular}

* Determined for only those samples which attained a well-defined limiting current

Fig. 2 Accelerated durability test results on the two most active catalysts: $\mathrm{BP}-\mathrm{Ph}-\mathrm{Fe}-\mathrm{Ar}$ and $\mathrm{BP}-\mathrm{Ph}-\mathrm{Fe}-\mathrm{Ar}-\mathrm{NH}_{3}$ at $1000 \mathrm{rpm}$ in $\mathrm{O}_{2}$ saturated $0.5 \mathrm{M}$ $\mathrm{H}_{2} \mathrm{SO}_{4}$ solution $(100 \mathrm{mV} / \mathrm{s}$, $1.2-0$ to $1.2 \mathrm{~V}$ ) The solid lines correspond to the initial activity and the dotted ones to the activity after 1000 cycles in $\mathrm{O}_{2}$ saturated electrolyte. The inset shows the high potential region of the main plot

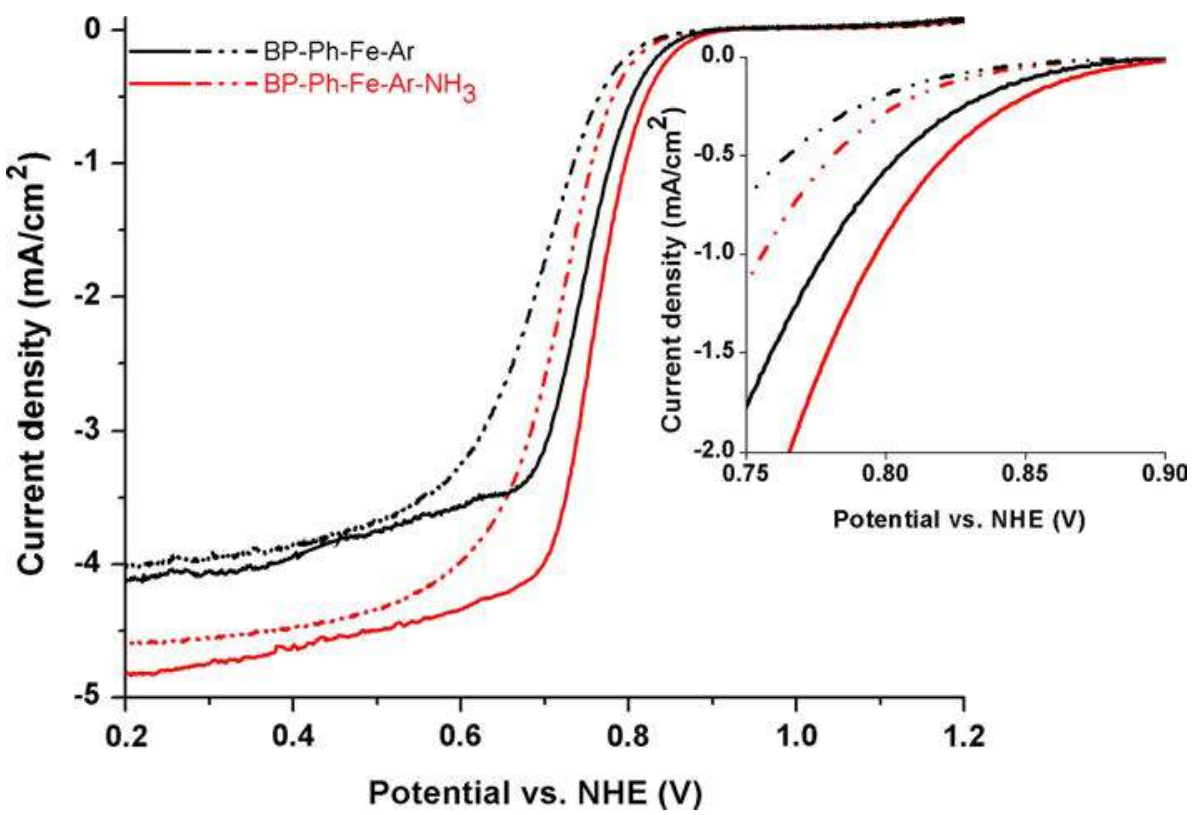

nitrogen functionalities are tabulated in Table 3. The assignments were based on literature [33, 50-55]. The sample BP-Ph which underwent no heat treatment exhibited only pyridinic-N. Although high pyridinic-N content has been shown to be a marker for ORR activity in $\mathrm{CN}_{\mathrm{x}}$ catalysts, this is not the case for samples studied here because BP-Ph showed very little ORR activity. Other heat-treated catalysts without iron showed presence of quaternary and pyrrolic species in addition to pyridinic- $\mathrm{N}$ species.

XPS spectra of samples containing iron are shown in Fig. 5. BP-Ph-Fe sample (Fig. 5a) has predominantly pyridinic-N species. Other species corresponding to higher B.E values such as quaternary- $\mathrm{N}$ and pyridinic- $\mathrm{N}^{+} \mathrm{O}^{-}$are observed for samples which have gone through the heattreatment steps (Fig. 5b, c). The peak noted in the B.E. range of 399.2-399.7 eV and associated with Fe-N species was observed only for heat-treated samples, namely BP$\mathrm{Ph}-\mathrm{Fe}-\mathrm{Ar}$ and $\mathrm{BP}-\mathrm{Ph}-\mathrm{Fe}-\mathrm{Ar}-\mathrm{NH}_{3}$. This is an important observation and points to the significance of $\mathrm{Fe}-\mathrm{N}_{\mathrm{x}}$ sites in imparting ORR activity to these materials. The $\mathrm{N} 1 \mathrm{~s}$ profile is similar for BP-Ph-Fe-Ar and BP-Ph-Fe-Ar- $\mathrm{NH}_{3}$ samples in general though the latter have relatively higher pyridinic-N content as noted in Table 2.

\subsubsection{Temperature Programmed Oxidation (TPO)}

Temperature programmed oxidation (TPO) experiments were performed using $10 \% \mathrm{O}_{2} / \mathrm{He}$. Results are presented in Fig. 6. As evident, a lower take-off temperature for carbon oxidation $(\mathrm{m} / \mathrm{z}=44$ signal) in case of samples containing iron (Fig. 6a, c) than their iron-free counterparts (Fig. 6b, d) is noted. This can be explained on the basis that iron is known to catalyze carbon oxidation. It is interesting to 


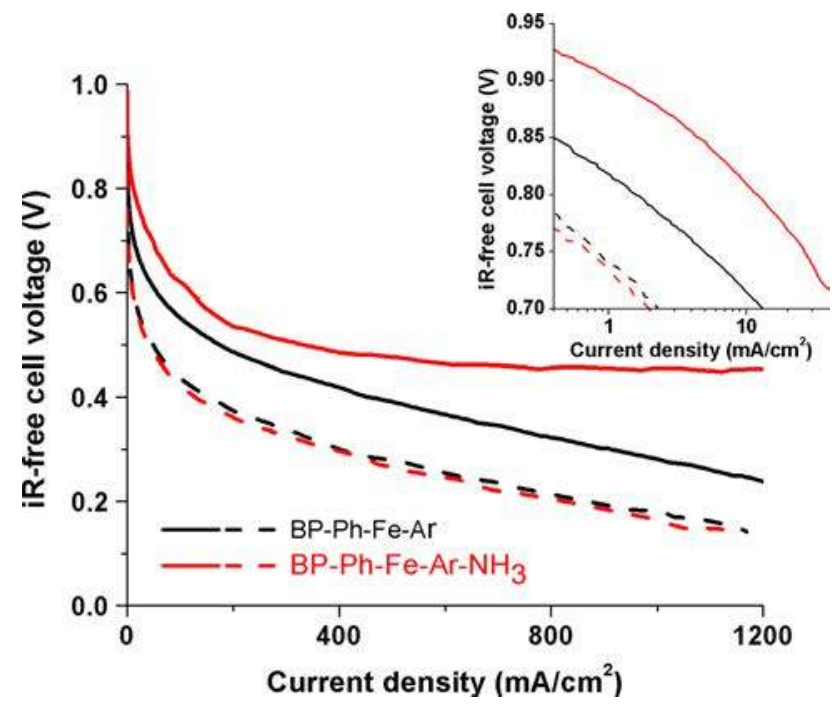

Fig. 3 Fuel-cell polarization curves before (solid lines) and after (dashed lines) $100 \mathrm{~h}$ potential hold at $0.5 \mathrm{~V}$ for BP-Ph-Fe-Ar and BP$\mathrm{Ph}-\mathrm{Fe}-\mathrm{Ar}-\mathrm{NH}_{3}$ catalysts. iR-free cell voltage vs. log of current density plots at high voltage region are shown as insets

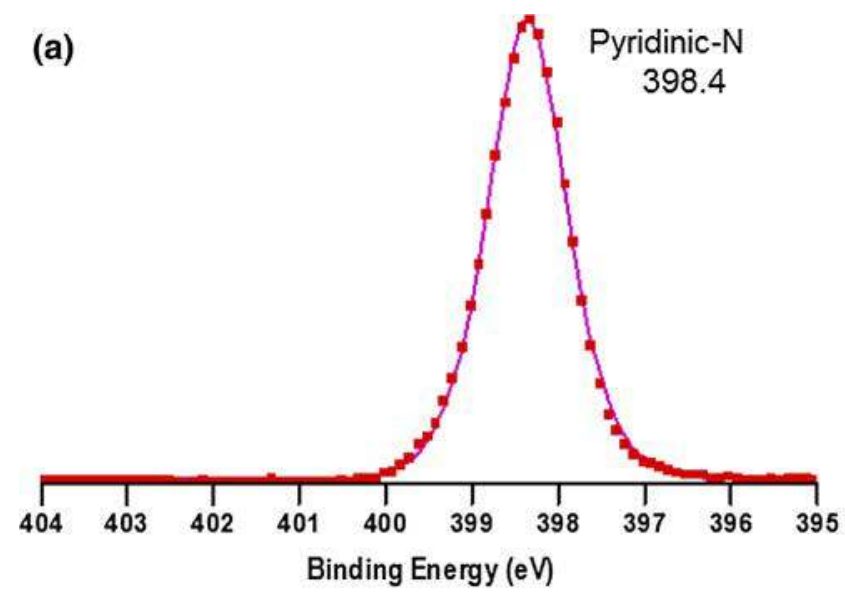

(c) Quaternary-N

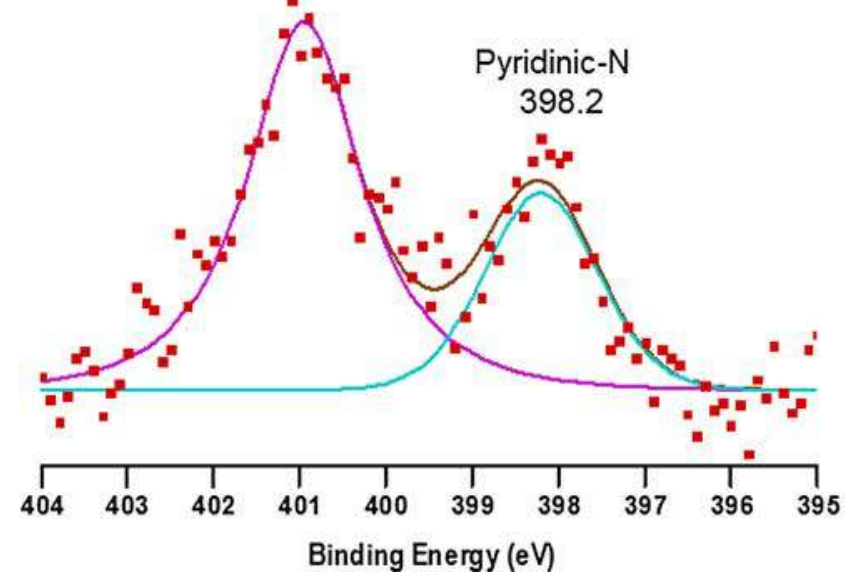

observe that the nitrogen species $(\mathrm{m} / \mathrm{z}=30$ signal $)$ evolve at higher temperatures than those noted for onset of carbon oxidation in case of samples containing iron (Fig. 6a, c). This can be attributed to the presence of nitrogen species (in coordination with $\mathrm{Fe}$ ) in the micropores of the support [12]. It is interesting to note that the TPO profiles were similar for BP-Ph-Ar and BP-Ph-Ar- $\mathrm{NH}_{3}$ as well as BP-Ph$\mathrm{Fe}-\mathrm{Ar}$ and BP-Ph-Fe-Ar-NH${ }_{3}$.

\subsubsection{X-ray Absorption Spectroscopy (XAS)}

XANES and EXAFS experiments on the Fe-K edge were also performed. Figure 7 a shows the XANES spectrum of the Fe-containing precursor (BP-Ph-Fe) which has not undergone any heat treatment. Spectra for $\mathrm{FeO}$ and $\mathrm{Fe}-$ acetate are shown as references. The spectrum for BP-Ph$\mathrm{Fe}$ suggests that iron exists in +2 oxidation state in this sample. This is expected because iron complexes with phenanthroline where it exists in +2 oxidation state.

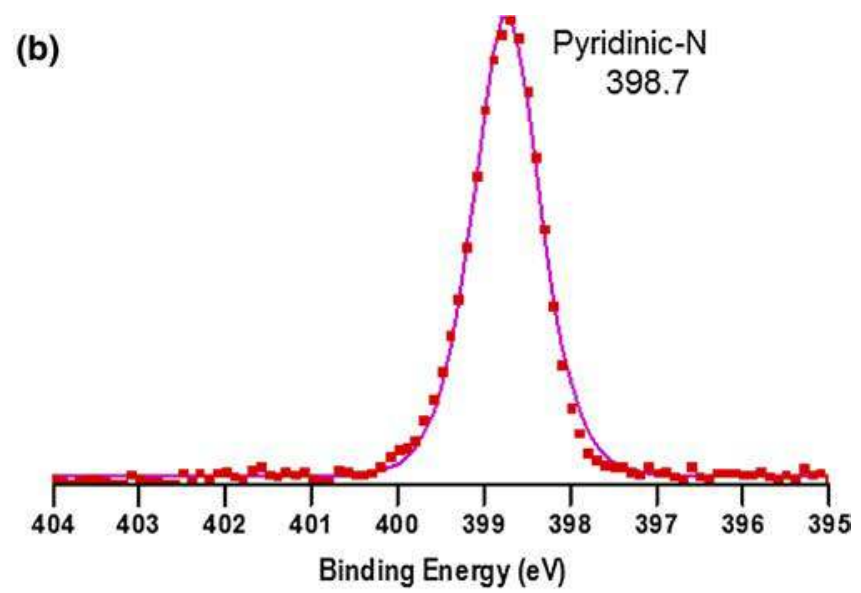

(d)

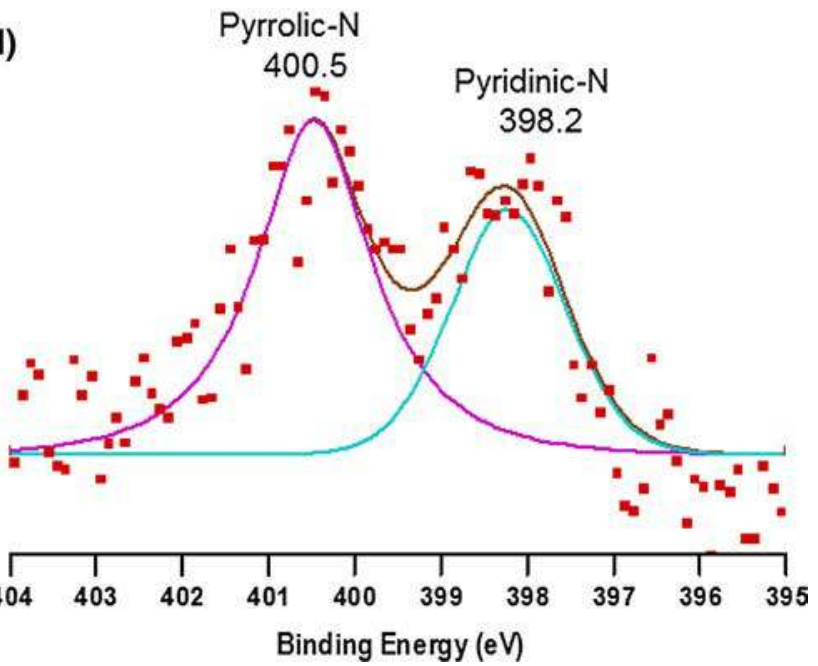

Fig. 4 N 1 s XPS spectra for various samples synthesized without iron. a Ph, b BP-Ph, c BP-Ph-Ar and d BP-Ph-Ar-NH 
Table 3 N 1 s distribution for various samples from XPS

\begin{tabular}{|c|c|c|c|c|c|}
\hline \multirow[t]{2}{*}{ Sample } & \multicolumn{5}{|c|}{ Relative percentage distribution } \\
\hline & $\begin{array}{l}\text { Pyridinic-N } \\
(398.2-398.9 \mathrm{eV}\end{array}$ & $\begin{array}{l}\mathrm{Fe}-\mathrm{N} \\
(399.2-399.7 \mathrm{eV})\end{array}$ & $\begin{array}{l}\text { Quaternary } \\
(400.9-401.0 \mathrm{eV})\end{array}$ & $\begin{array}{l}\text { Pyrrolic } \\
(400.4-400.5 \mathrm{eV})\end{array}$ & $\begin{array}{l}\text { Pyridinic- } \mathrm{N}^{+} \mathrm{O}^{-} \\
(>402 \mathrm{eV})\end{array}$ \\
\hline $\mathrm{Ph}$ & 100 & & - & - & - \\
\hline $\mathrm{BP}-\mathrm{Ph}$ & 100 & & - & - & - \\
\hline $\mathrm{BP}-\mathrm{Ph}-\mathrm{Ar}$ & 31 & & 69 & - & \\
\hline $\mathrm{BP}-\mathrm{Ph}-\mathrm{Ar}-\mathrm{NH}_{3}$ & 39 & & 61 & - & - \\
\hline $\mathrm{BP}-\mathrm{Ph}-\mathrm{Fe}$ & 94 & & & 6 & - \\
\hline $\mathrm{BP}-\mathrm{Ph}-\mathrm{Fe}-\mathrm{Ar}$ & 17 & 5 & 67 & - & 11 \\
\hline $\begin{array}{l}\text { BP-Ph-Fe-Ar- } \\
\mathrm{NH}_{3}\end{array}$ & 35 & 6 & 54 & - & 5 \\
\hline
\end{tabular}

Spectra for BP-Ph-Fe-Ar and BP-Ph-Fe-Ar- $\mathrm{NH}_{3}$ are shown in Fig. 7b. Spectra for Fe-carbide are also included. There was no significant difference in the spectra between the spectra for BP-Ph-Fe-Ar and BP-Ph-Fe-Ar- $\mathrm{NH}_{3}$ samples and they both resembled to iron carbide reference spectra. However, the possibility of the existence of $\mathrm{Fe}-\mathrm{N}_{\mathrm{x}}$ cannot be discounted.

We next compared the FT magnitudes of BP-Ph-Fe, BP$\mathrm{Ph}-\mathrm{Fe}-\mathrm{Ar}$ and $\mathrm{BP}-\mathrm{Ph}-\mathrm{Fe}-\mathrm{Ar}-\mathrm{NH}_{3}$ samples with that of iron carbide reference. EXAFS results presented in Fig. 7c and $\mathrm{d}$ are also in agreement with XANES results where it is indicated that the spectra for BP-Ph-Fe-Ar and BP-Ph-FeAr- $\mathrm{NH}_{3}$ samples were similar to that for iron carbide with $\mathrm{Fe}-\mathrm{Fe}$ peak appearing at $2.1 \AA[30,31,56]$. A small shoulder at $\sim 1.5 \AA$ can be attributed to $\mathrm{Fe}-\mathrm{C}_{\mathrm{x}}$ or $\mathrm{Fe}-\mathrm{N}_{\mathrm{x}}$ type scatter [30, 31, 56-60]. The coordination environment for $\mathrm{BP}-\mathrm{Ph}-\mathrm{Fe}$ sample is similar to that for iron-acetate. Though we do not distinguish between iron carbide or iron nitride here, an important finding that does emerge from both XANES and EXAFS analysis is that there is a marked change in the oxidation state as well as the coordination environment of iron after the first heat-treatment step in argon. The second pyrolysis in ammonia does not change the nature of iron species in the catalyst but leads to an improvement in ORR activity as discussed previously.

\subsection{5 ${ }^{57}$ Fe Mössbauer Spectroscopy}

Mössbauer spectroscopy was used to determine various iron species in these catalysts. The Mössbauer spectra for BP-Ph-Fe, BP-Ph-Fe-Ar and BP-Ph-Fe-Ar-NH $\mathrm{NH}_{3}$ samples are shown in Fig. 8 and the Mössbauer parameters with corresponding assignments are presented in Table 4. The primary species for BP-Ph-Fe sample was associated with the doublet in the spectra and assigned to iron nitride, $\mathrm{Fe}_{\mathrm{x}} \mathrm{N}$ $(\mathrm{x} \leq 2.1)[15,18,61-63]$. In addition, there was a very small contribution coming from the sextet $\left(\mathrm{H}_{0}\right.$ around 27
T) which corresponds to carbide phase of Martensite type $\left(\mathrm{Fe}^{0}\right.$ with 1-2 wt\% C) [64].

The spectra for BP-Ph-Fe-Ar and BP-Ph-Fe-Ar- $\mathrm{NH}_{3}$ samples were found to be very similar and six iron species were identified for each. The singlet characterized by an isomer shift $\left(\delta_{\text {iso }}\right)$ of $-0.05 \mathrm{~mm} / \mathrm{s}$ was assigned to superparamagnetic iron [15, 62, 63, 65-68]. Presence of this phase of iron was also confirmed using Superconducting Quantum Interference Device (SQUID) magnetometry where negligible hysteresis was noted between magnetization (M) as a function of field $(\mathrm{H})$ curve, as discussed later. Two doublets corresponding to $\mathrm{FeN}_{4}$ species with different spin states of iron were also observed for both samples [18, 62, 63, 65-67, 69]. The doublet corresponding to planar $\mathrm{FeN}_{4}$ acted as a dominant species in both. This doublet corresponding to $\mathrm{Fe}^{2+}$ ion in low spin state and coordinated to four pyrrolic nitrogen groups connected to surface of carbon support has been reported to correlate with ORR activity by several previous reports [15, 62, 65]. Similar observations are also made in this work and findings related to this are discussed later in the manuscript. In addition, the sextets corresponding to $33 \mathrm{~T}$ and $21 \mathrm{~T}$ were assigned to $\mathrm{Fe}^{0}[15,21,63,67,70]$ and $\mathrm{Fe}_{3} \mathrm{C}$ $[15,21,66,70,71]$ respectively. Significant amounts of these species were noted for both samples. Thus, Mössbauer results also support XAS findings and suggest identical iron species for BP-Ph-Fe-Ar and BP-Ph-Fe-Ar- $\mathrm{NH}_{3}$ samples.

\subsection{Acid-Washing as a Probe}

\subsubsection{Effect of Acid Washing on Half-Cell and Fuel Cell Performance}

The effect of acid-washing on ORR activities of BP-Ph-FeAr and BP-Ph-Fe-Ar- $\mathrm{NH}_{3}$ samples is compared in Fig. 9. It should be noted that acid-washing is merely used as a probe to gain insights into the nature of active sites in these 

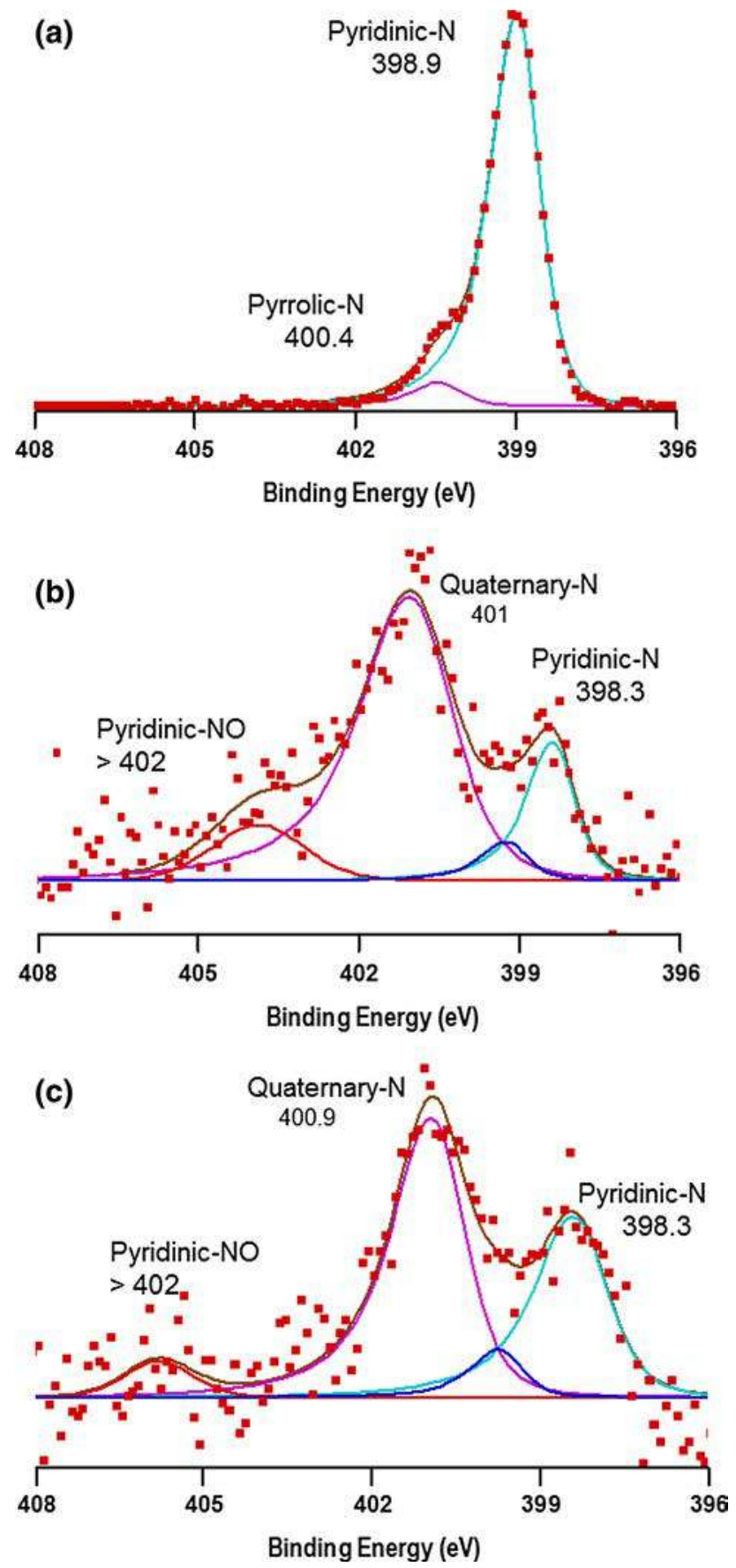

Fig. 5 N 1 s XPS spectra for various samples synthesized with iron. a $\mathrm{BP}-\mathrm{Ph}-\mathrm{Fe}$, b BP-Ph-Fe-Ar and c BP-Ph-Fe-Ar- $\mathrm{NH}_{3}$

materials. It is evident that acid-washing produces a marked decrease in ORR activity for both samples as clear from the reduced onset potentials for the two washed samples relative to their unwashed counterparts (Table 5). The half-wave potential $\left(\mathrm{E}_{1 / 2}\right)$ was reduced by $30 \mathrm{mV}$ and $20 \mathrm{mV}$ after acid-washing for BP-Ph-Fe-Ar and BP-Ph-FeAr- $\mathrm{NH}_{3}$, respectively. The specific kinetic current $\left(\mathrm{i}_{\mathrm{K}}\right)$ values at $0.75 \mathrm{~V}$ were observed to reduce by 60 and $48 \%$

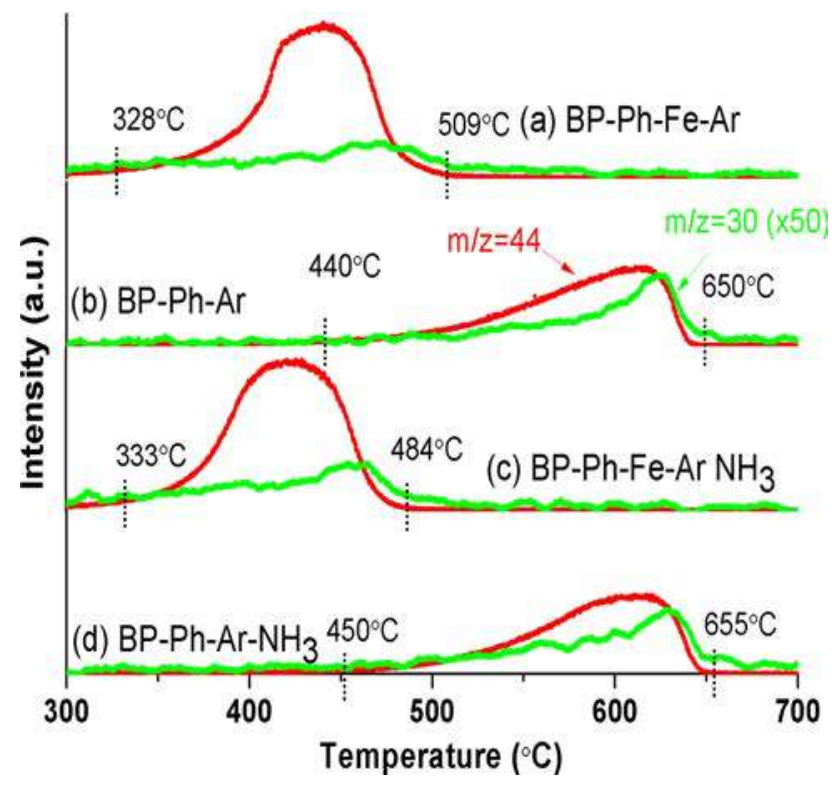

Fig. 6 Comparison of temperature programmed oxidation (TPO) Profiles for samples with and without iron

after acid-washing for BP-Ph-Fe-Ar and BP-Ph-Fe-Ar-NH samples respectively. Corresponding decrease in ORR rate constant $(\mathrm{k})$ after acid-washing was also noted (Table 5). This decrease in activity is explained by the fact that acidwashing removes some of the surface iron from the $\mathrm{Fe}$ based ORR active sites in these materials. This explanation is also supported by our ICP-OES measurements published previously [30] where acid-washing was noted to bring about a steady removal of iron from the sample.

It is interesting to note that acid-washing however did not change the ORR pathway for both BP-Ph-Fe-Ar and BP-Ph-Fe-Ar- $\mathrm{NH}_{3}$ samples. The selectivity of these samples both before and after acid-washing was found to be close to 4 as evident from the inset of Fig. 9.

One of the motivations of this study is to attempt to benchmark non-noble metal ORR catalysts testing and activity measurements. First of all, the electrical double layer capacitance $\left(\mathrm{C}_{\mathrm{dl}}\right)$ values for the four most active catalysts in this study namely BP-Ph-Fe-Ar, BP-Ph-Fe-Arwashed, $\mathrm{BP}-\mathrm{Ph}-\mathrm{Fe}-\mathrm{Ar}-\mathrm{NH}_{3}$ and $\mathrm{BP}-\mathrm{Ph}-\mathrm{Fe}-\mathrm{Ar}-\mathrm{NH}_{3}$-washed were measured. Electrical double layer capacitance $\left(\mathrm{C}_{\mathrm{dl}}\right)$ values were then used to obtain electrochemically accessible surface area (EASA) and roughness factor (RF) values, as described in Eq. 4.

Figure 10a presents the $\mathrm{CVs}$ at various scan rates for the representative $\mathrm{BP}-\mathrm{Ph}-\mathrm{Fe}-\mathrm{Ar}-\mathrm{NH}_{3}$ sample in argon saturated $0.5 \mathrm{M} \mathrm{H}_{2} \mathrm{SO}_{4}$. These $\mathrm{CVs}$ were collected in a potential range (from 1.2 to 1.0 to $1.2 \mathrm{~V}$ vs. NHE) where no Faradaic processes were observed to occur. The current here is entirely capacitive and arises due to double-layer charging. This is also supported by the linear nature of the current vs. 

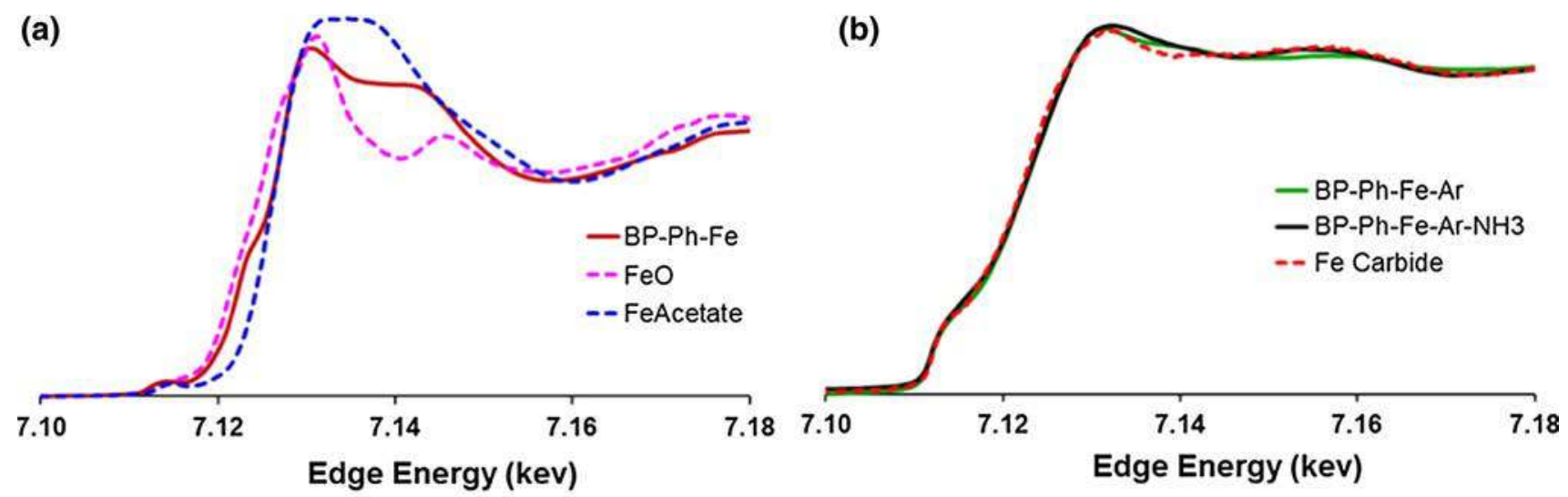

(c)

(d)
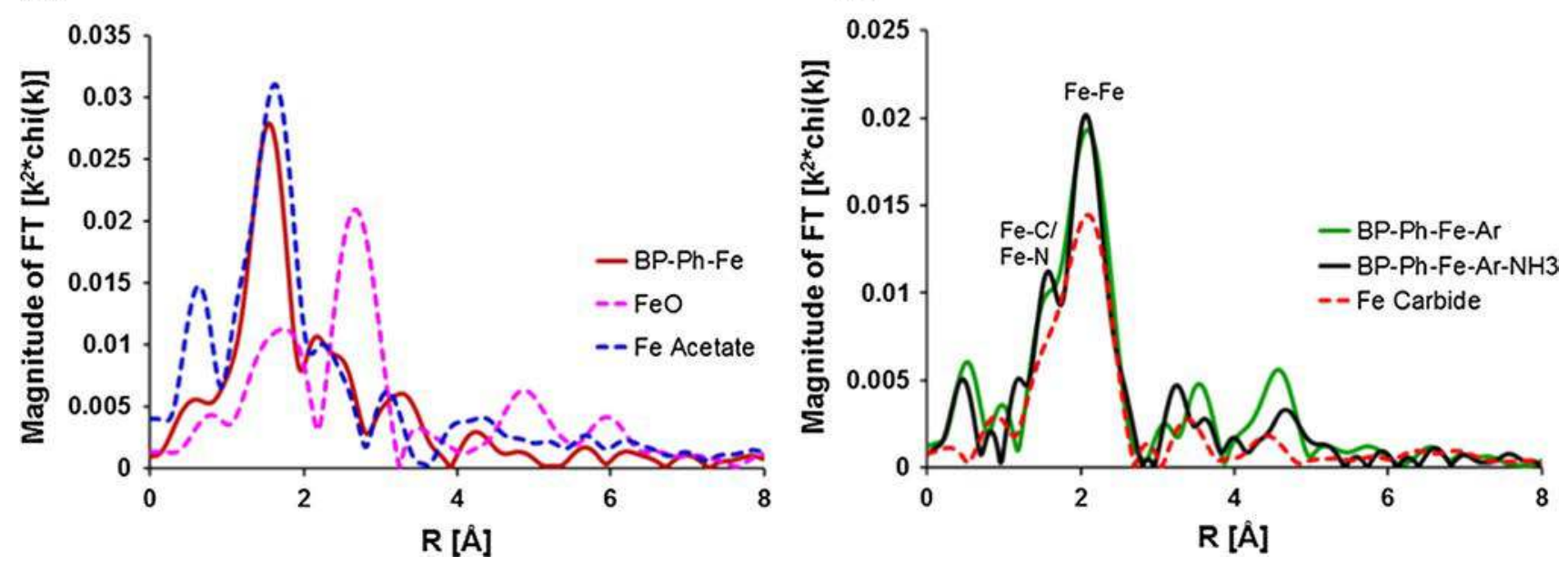

Fig. 7 Fe-K edge XAS spectra for BP-Ph-Fe, BP-Ph-Fe-Ar and BP-Ph-Fe-Ar-NH 3 . a, b XANES, c, d EXAFS. Reference spectra for FeO, Fe Acetate and $\mathrm{Fe}$ carbide are also included for comparison

scan rate plots for various samples (Fig. 10b). The slopes of these plots corresponded to $\mathrm{C}_{\mathrm{dl}}$ values which in-turn were used to obtain EASA and RF values for various samples (Table 6). EASA and RF values for BP-Ph-Fe-Ar$\mathrm{NH}_{3}$ are much higher than that for BP-Ph-Fe-Ar and BP$\mathrm{Ph}-\mathrm{Fe}-\mathrm{Ar}-\mathrm{NH}_{3}$-washed samples.

We next examined the correlation of ORR activity of these four samples with their EASA and RF values. Results are presented in Fig. 10c and d respectively. Specific kinetic current density $\left(i_{K}\right)$ increased linearly with increase in EASA (Fig. 10c) as well as that in RF (Fig. 10d). This implies that higher ORR activity of BP-Ph-Fe-Ar- $\mathrm{NH}_{3}$ sample relative to BP-Ph-Fe-Ar or BP-Ph-Fe-Ar- $\mathrm{NH}_{3^{-}}$ washed samples as noted previously is related to higher density of active sites in BP-Ph-Fe-Ar- $\mathrm{NH}_{3}$ catalyst. This hypothesis is also supported by site density (SD) calculations from Mössbauer analysis presented later in the manuscript.

The non-zero intercepts in Fig. 10c and d are quite expected considering that part of the double layer capacitance arises from inactive components (such as carbon) in these catalysts. However, isolating such contributions is beyond the scope of this work and will not be dealt here. Nevertheless, this analysis allows one to make reasonable predictions for ORR activity if EASA and RF values are known.

The fuel cell polarization curves for various samples are presented in Fig. 11. BP-Ph-Fe-Ar sample had higher initial activity than BP-Ph-Fe-Ar-washed sample in agreement with half-cell results, but both samples attained very similar activity after $100 \mathrm{~h}$ potential hold (Fig. 11a). Similar trends were noted in Fig. 11b where BP-Ph-Fe-Ar-NH sample exhibited higher initial activity than BP-Ph-Fe-Ar$\mathrm{NH}_{3}$-washed sample, but the activity of the two samples was very similar after the potential hold. Comparison of ORR activities of the two washed samples, namely BP-Ph$\mathrm{Fe}-\mathrm{Ar}$-washed and BP-Ph-Fe-Ar-NH -washed (Fig. 11c) shows that $\mathrm{NH}_{3}$-treated sample has again relatively higher initial activity, but after $100 \mathrm{~h}$ potential hold, the two samples exhibited comparable activities. These results imply a higher stability for acid-washed samples relative to their unwashed counterparts. Furthermore, the magnitude of the loss in activity caused by acid-washing or a potential hold is similar. 
Fig. 8 Deconvoluted Mössbauer Spectra for a $\mathrm{BP}-\mathrm{Ph}$ $\mathrm{Fe}$, b BP-Ph-Fe-Ar and c BP$\mathrm{Ph}-\mathrm{Fe}-\mathrm{Ar}-\mathrm{NH}_{3}$. Insets show the low-intensity species (a)

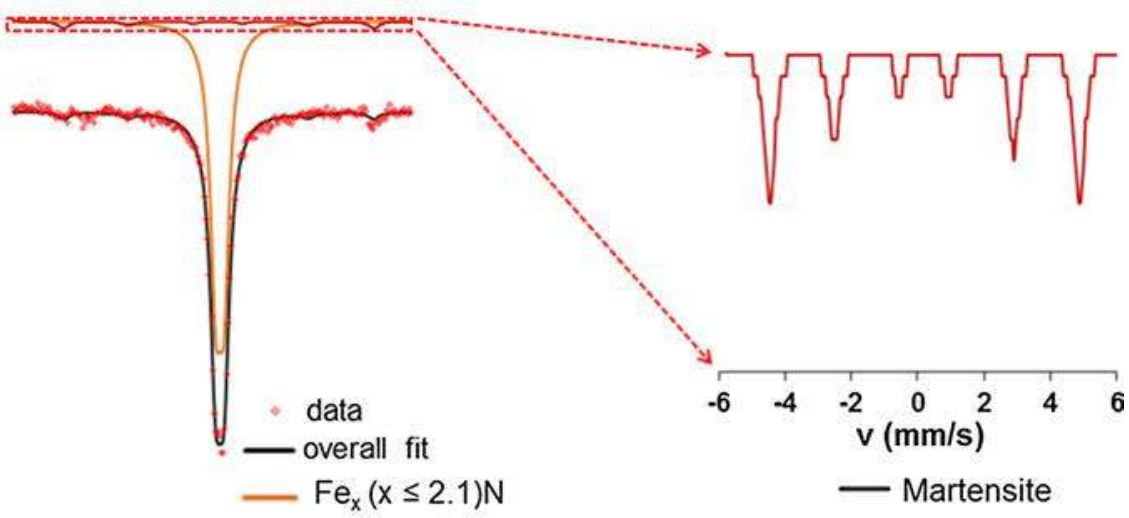

(b)
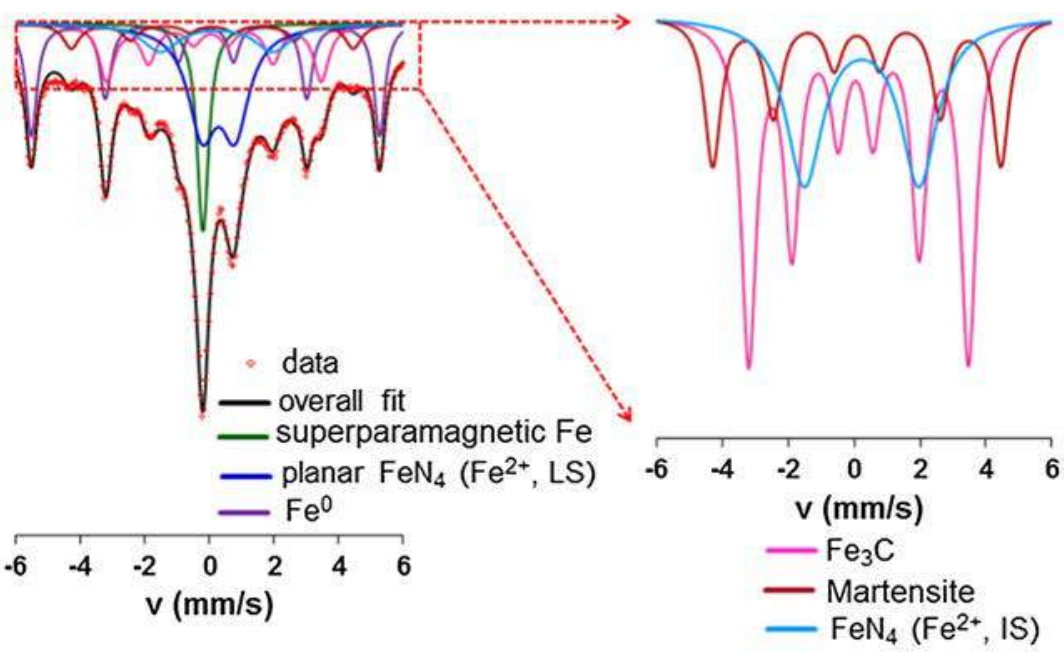

(c)

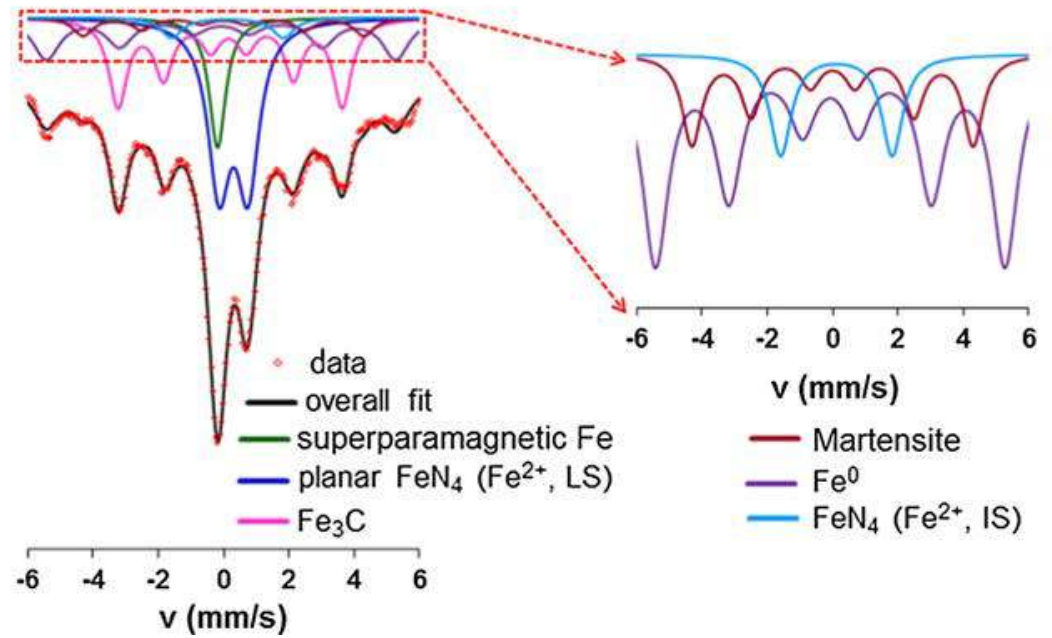

\subsubsection{Effect of Acid Washing on the Distribution of Surface} $N$ Species (XPS)

To analyze the nature of surface species before and after acid-washing, X-ray photoelectron spectroscopy (XPS) was used. Results are shown in Fig. 12. The nature of nitrogen species on the surface is the same before and after acid-washing for both BP-Ph-Fe-Ar and BP-Ph-Fe-Ar- $\mathrm{NH}_{3}$ samples. However, both acid-washed samples had significantly increased relative pyridinic- $\mathrm{N}$ content after acid- 
Table 4 Mössbauer parameters for various samples and the corresponding assignments

\begin{tabular}{|c|c|c|c|c|c|c|}
\hline Sample & $\begin{array}{l}\delta_{\text {iso }}(\%) \\
\mathrm{mm} / \mathrm{s}\end{array}$ & $\begin{array}{l}\Delta \mathrm{E}_{\mathrm{Q}} \\
\mathrm{mm} / \mathrm{s}\end{array}$ & $\begin{array}{l}\mathrm{H}_{0} \\
\mathrm{~T}\end{array}$ & $\begin{array}{l}\text { Rel Int } \\
\%\end{array}$ & Assignment & Reference \\
\hline \multirow[t]{2}{*}{$\mathrm{BP}-\mathrm{Ph}-\mathrm{Fe}$} & 0.30 & 0.25 & 0.0 & 94 & $\mathrm{Fe}_{\mathrm{x}} \mathrm{N}$ with $\mathrm{x} \leq 2.1$ & {$[15,18,61-63]$} \\
\hline & 0.19 & 0.00 & 28.8 & 6 & Martensite & {$[64]$} \\
\hline \multirow[t]{6}{*}{ BP-Ph-Fe-Ar } & -0.05 & 0.00 & 0.0 & 13 & Superparamagnetic iron & {$[15,63,65-68]$} \\
\hline & 0.03 & 0.00 & 33.4 & 25 & $\mathrm{Fe}^{0}$ & {$[15,21,63,67,70]$} \\
\hline & 0.23 & 0.09 & 20.6 & 17 & $\mathrm{Fe}_{3} \mathrm{C}$ & {$[15,21,66,70,71]$} \\
\hline & 0.23 & 0.00 & 27.0 & 8 & Martensite & {$[64]$} \\
\hline & 0.42 & 1.01 & 0.0 & 28 & Planar $\mathrm{FeN}_{4}\left(\mathrm{Fe}^{2+}\right.$, low spin $)$ & {$[18,62,63,65-67,69]$} \\
\hline & 0.37 & 3.46 & 0.0 & 9 & $\mathrm{FeN}_{4}\left(\mathrm{Fe}^{2+}\right.$, intermediate spin $)$ & {$[18,62,63,65-67,69]$} \\
\hline \multirow[t]{7}{*}{ BP-Ph-Fe-Ar-NH ${ }_{3}$} & -0.05 & 0.00 & 0.0 & 9 & Superparamagnetic iron & {$[15,62,63,65-68]$} \\
\hline & 0.04 & 0.00 & 33.1 & 18 & $\mathrm{Fe}^{0}$ & {$[15,21,63,67,70]$} \\
\hline & 0.31 & 0.05 & 21.2 & 28 & $\mathrm{Fe}_{3} \mathrm{C}$ & {$[15,21,64,66,70,71]$} \\
\hline & & & & & Martensite & \\
\hline & 0.20 & 0.00 & 26.7 & 7 & Planar $\mathrm{FeN}_{4}\left(\mathrm{Fe}^{2+}\right.$, low spin $)$ & {$[18,62,63,65-67,69]$} \\
\hline & 0.43 & 0.89 & 0.0 & 33 & $\mathrm{FeN}_{4}\left(\mathrm{Fe}^{2+}\right.$, intermediate spin $)$ & {$[18,62,63,65-67,69]$} \\
\hline & 0.24 & 3.41 & 0.0 & 5 & & \\
\hline
\end{tabular}

Fig. 9 Comparison of ORR $\mathrm{RDE}$ results for BP-Ph-Fe-Ar and $\mathrm{BP}-\mathrm{Ph}-\mathrm{Fe}-\mathrm{Ar}-\mathrm{NH}_{3}$ catalysts at $1000 \mathrm{rpm}$ in $0.5 \mathrm{M} \mathrm{H}_{2} \mathrm{SO}_{4}$ oxygen-saturated solution both before and after acid-washing. The inset represents KoutechyLevich plots at $0.5 \mathrm{~V}$ for various samples. Also, included is the theoretical line corresponding to selectivity 4

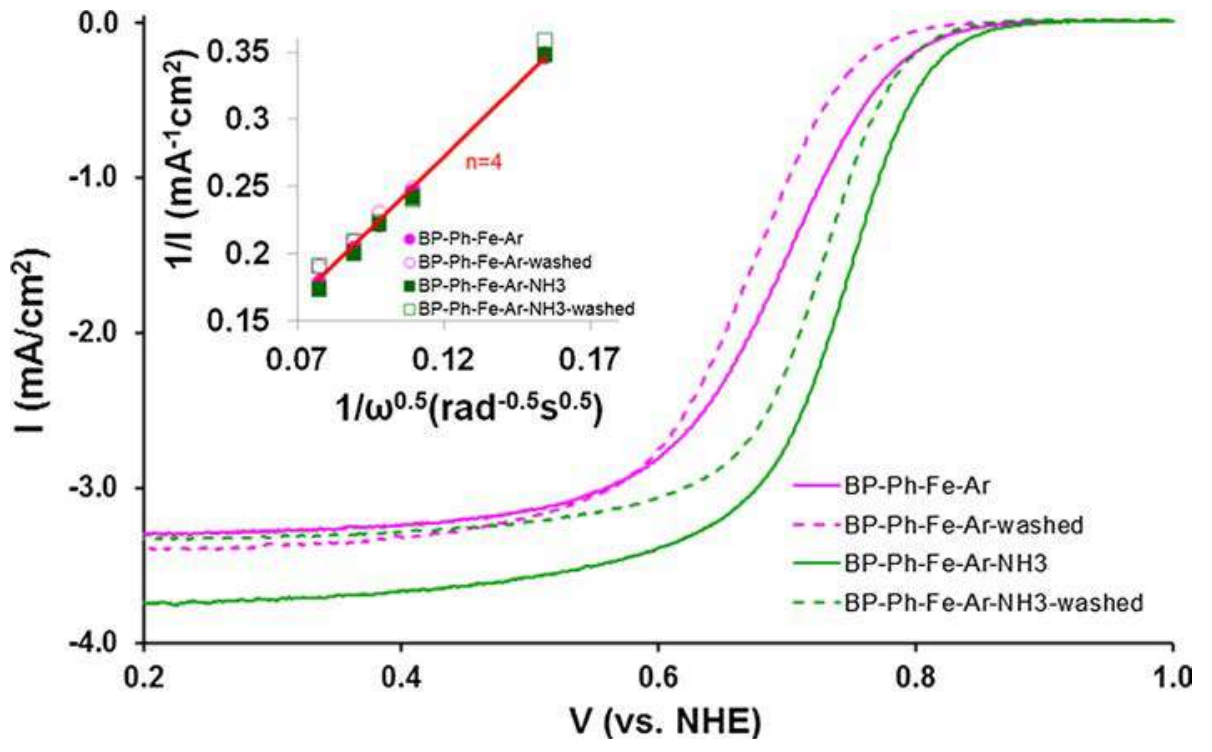

Table 5 Comparison of ORR kinetic parameters for BP-Ph-Fe-Ar and BP-Ph-Fe-Ar-NH $\mathrm{NH}_{3}$ before and after acid-washing

\begin{tabular}{|c|c|c|c|c|}
\hline Sample & $\begin{array}{l}\text { Onset potential (V vs. NHE@ - } \\
0.1 \mathrm{~mA} / \mathrm{cm} 2 \text { ) }\end{array}$ & $\begin{array}{l}\text { Half-wave potential }\left(\mathrm{E}_{1 / 2}\right) \text { (V vs. } \\
\text { NHE) }\end{array}$ & $\begin{array}{l}\mathrm{i}_{\mathrm{K}} @ 0.75 \mathrm{~V}(\mathrm{~mA} / \\
\left.\mathrm{mg}_{\text {catalyst }}\right)\end{array}$ & $\begin{array}{l}\mathrm{k}(\mathrm{x} 100)\left(\mathrm{cm}^{3} /\right. \\
\text { s.g }\end{array}$ \\
\hline BP-Ph-Fe-Ar & 0.82 & 0.69 & 1.0 & 0.214 \\
\hline BP-Ph-Fe-Ar-washed & 0.78 & 0.66 & 0.4 & 0.078 \\
\hline BP-Ph-Fe-Ar-NH 3 & 0.84 & 0.74 & 3.3 & 0.677 \\
\hline $\begin{array}{l}\mathrm{BP}-\mathrm{Ph}-\mathrm{Fe}-\mathrm{Ar}-\mathrm{NH}_{3}- \\
\text { washed }\end{array}$ & 0.81 & 0.72 & 1.7 & 0.339 \\
\hline
\end{tabular}


(a)

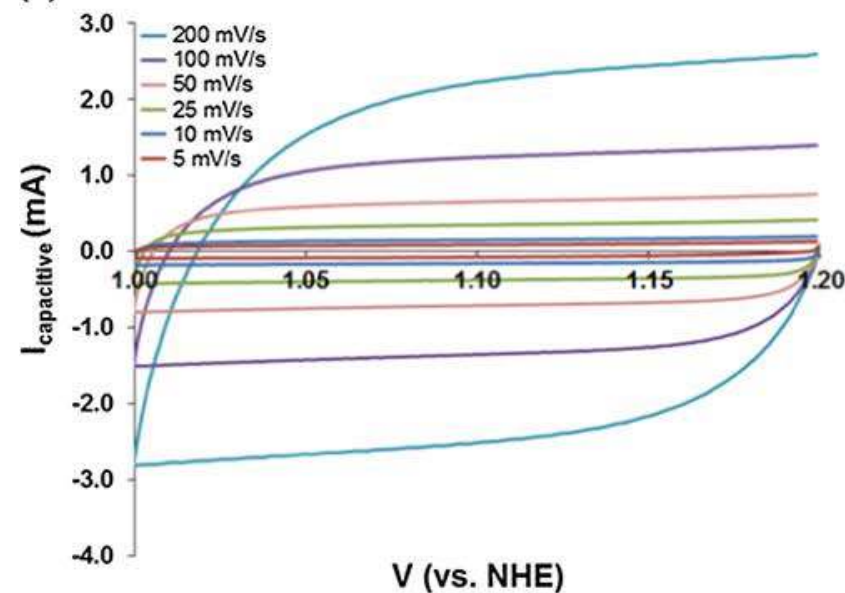

(c)

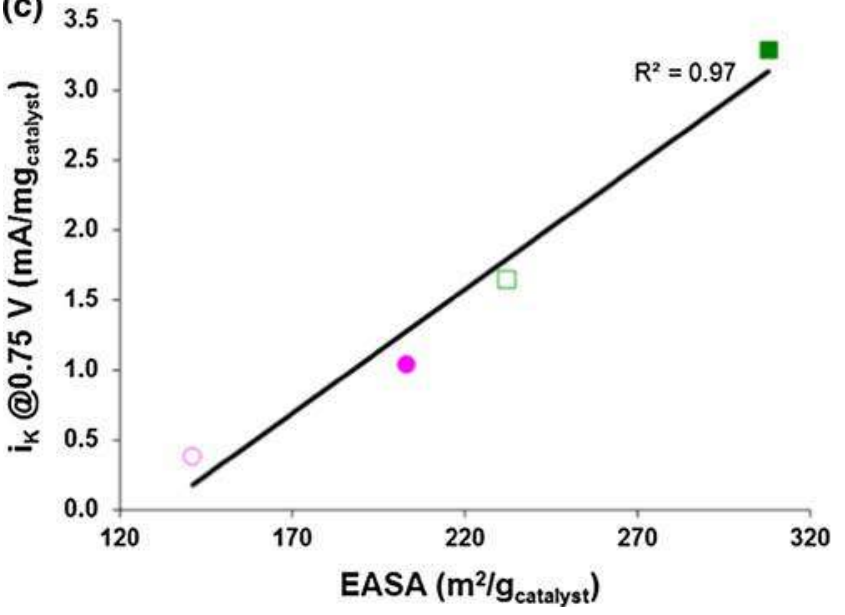

Fig. 10 a Cyclic voltammograms at various scan rates for $\mathrm{BP}-\mathrm{Ph}-\mathrm{Fe}-$ Ar- $\mathrm{NH}_{3}$ collected in a potential window without Faradaic processes. The capacitive current at $1.1 \mathrm{~V}$ vs. scan rate is presented in $\mathbf{b}$ for BP$\mathrm{Ph}-\mathrm{Fe}-\mathrm{Ar}$, BP-Ph-Fe-Ar-washed, BP-Ph-Fe-Ar-NH $\mathrm{NH}_{3}$ and BP-Ph-Fe-

Table 6 Comparison of double layer capacitance $\left(\mathrm{C}_{\mathrm{dl}}\right)$, electrochemically accessible surface area (EASA) and roughness factor (RF) values for BP-Ph-Fe-Ar and BP-Ph-Fe-Ar- $\mathrm{NH}_{3}$ before and after acidwashing

\begin{tabular}{|c|c|c|c|}
\hline Sample & $\mathrm{C}_{\mathrm{dl}}(\mathrm{mF})$ & $\operatorname{EASA}\left(\mathrm{m}^{2} / \mathrm{g}_{\text {catalyst }}\right)$ & $\mathrm{RF}$ \\
\hline BP-Ph-Fe-Ar & 8 & 203 & 1627 \\
\hline BP-Ph-Fe-Ar-washed & 6 & 141 & 1130 \\
\hline $\mathrm{BP}-\mathrm{Ph}-\mathrm{Fe}-\mathrm{Ar}-\mathrm{NH}_{3}$ & 12 & 308 & 2461 \\
\hline $\mathrm{BP}-\mathrm{Ph}-\mathrm{Fe}-\mathrm{Ar}-\mathrm{NH}_{3}$-washed & 9 & 232 & 1855 \\
\hline
\end{tabular}

washing (Table 7). Removal of iron from the surface caused by acid-washing is believed to expose the edge nitrogen causing an increase in the relative fraction of pyridinic-N functionalities on the surface.
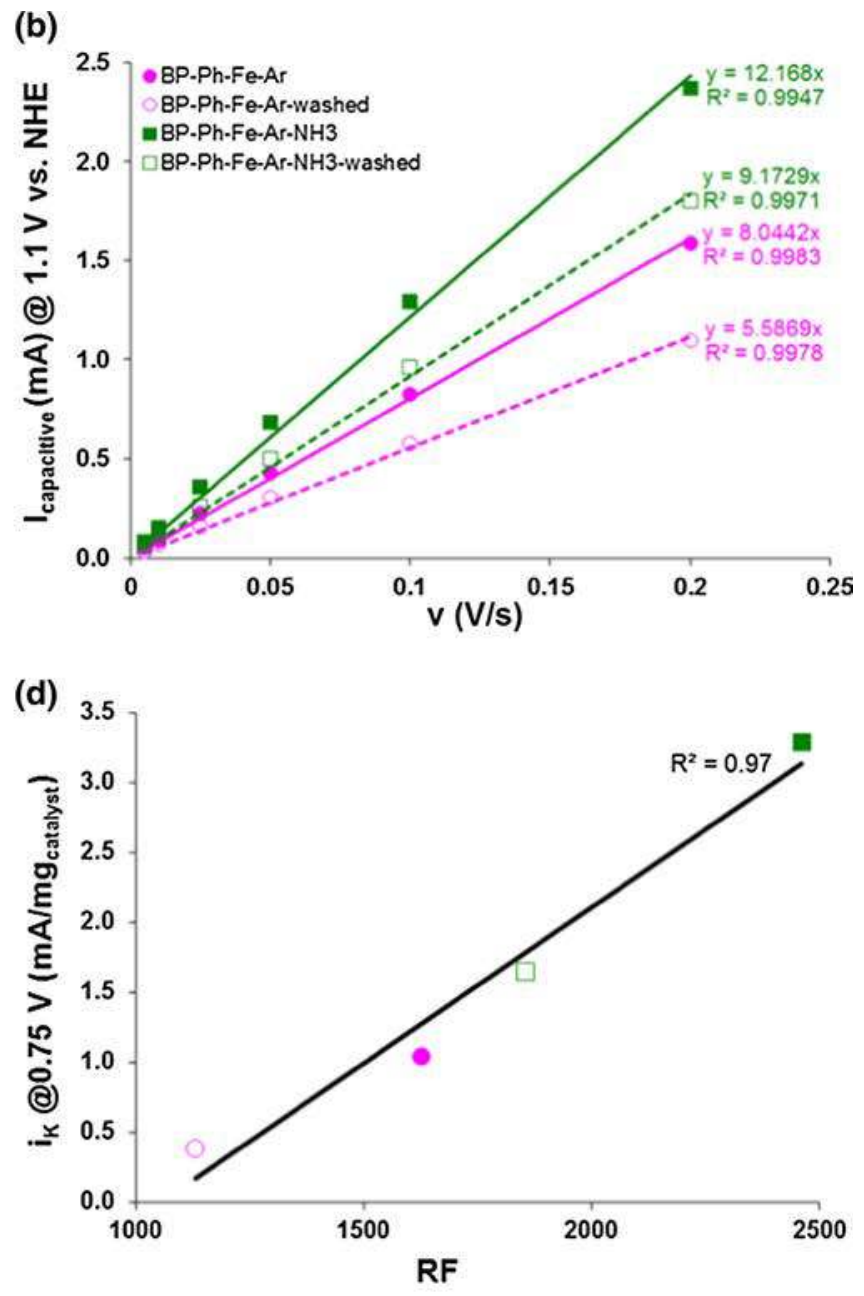

Ar- $\mathrm{NH}_{3}$-washed. The corresponding kinetic current at $0.75 \mathrm{~V}$ for these four samples as a function of their c electrochemically accessible surface areas and $\mathbf{d}$ roughness factors

\subsubsection{Effect of Acid Washing on the Nature of Fe Species $(X A S)$}

Comparison of XANES spectra for BP-Ph-Fe-Ar and its washed counterpart (BP-Ph-Fe-Ar-washed) suggests that acid-washing does not change the nature of iron species (Fig. 13a). Spectra for both samples resembled to that of iron carbide though contribution from iron nitride is also quite likely, as discussed previously. Similar behavior was noted in case of BP-Ph-Fe-Ar- $\mathrm{NH}_{3}$ sample where its spectra showed similarities with that of iron carbide reference both before and after washing (Fig. 13b). The findings from XANES experiments were also corroborated with EXAFS results. EXAFS spectra for BP-Ph-Fe-Ar and $\mathrm{BP}-\mathrm{Ph}$-Fe-Ar-washed samples (Fig. 13c) were very similar to that of iron carbide with $\mathrm{Fe}-\mathrm{Fe}$ peak appearing at $2.1 \AA$. A small shoulder at $\sim 1.5 \AA$ can be attributed to $\mathrm{Fe}-\mathrm{C}_{\mathrm{x}}$ type 

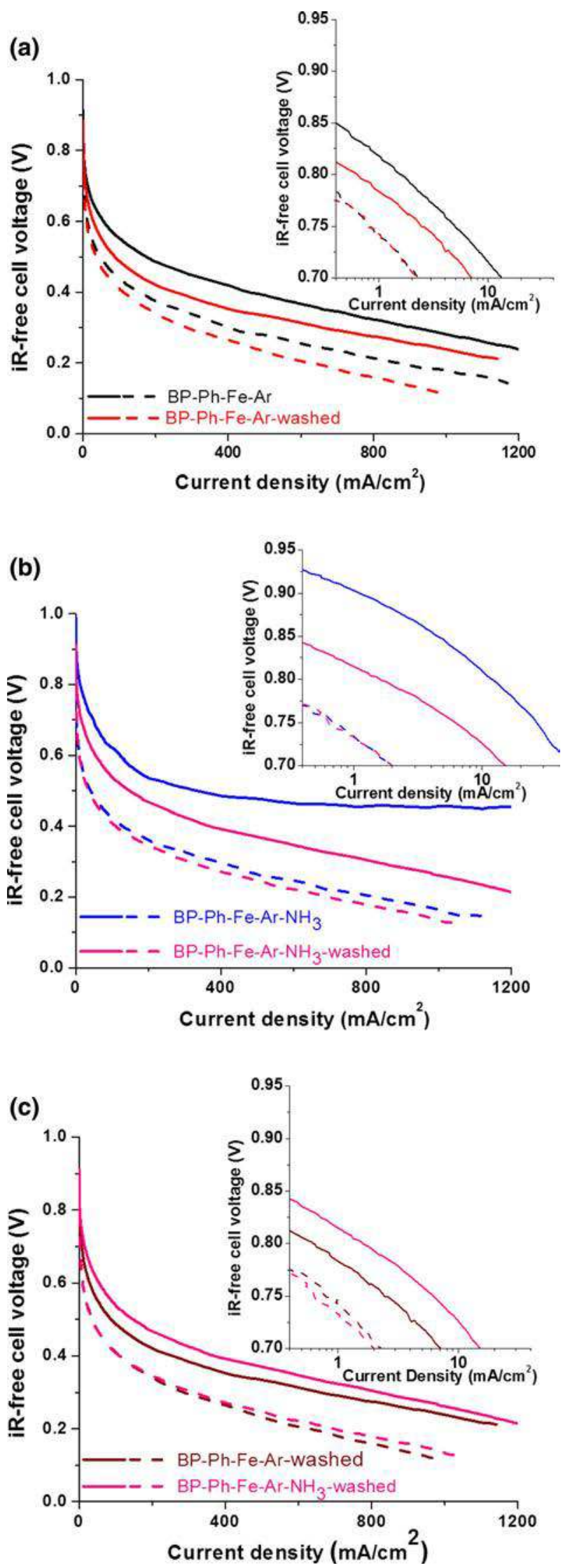

Tig. 11 Fuel-cell polarization curves (solid lines) and after (dashed lines) $100 \mathrm{~h}$ potential hold at $0.5 \mathrm{~V}$ for a $\mathrm{BP}-\mathrm{Ph}-\mathrm{Fe}-\mathrm{Ar}$ and $\mathrm{BP}-\mathrm{Ph}-\mathrm{Fe}-$ Ar-washed, b BP-Ph-Fe-Ar- $\mathrm{NH}_{3}$ and BP-Ph-Fe-Ar- $\mathrm{NH}_{3}$-washed and c $\mathrm{BP}-\mathrm{Ph}-\mathrm{Fe}-\mathrm{Ar}$-washed and $\mathrm{BP}-\mathrm{Ph}-\mathrm{Fe}-\mathrm{Ar}-\mathrm{NH}_{3}$-washed. iR-free cell voltage vs. log of current density plots at high voltage region are shown as insets

scatter although contribution from $\mathrm{Fe}$ nitride cannot be ruled out. Similar trends were noted for BP-Ph-Fe-Ar- $\mathrm{NH}_{3}$ sample (Fig. 13d). The important insight provided by the XAS analysis is that the iron oxidation state and coordination environment remain unaltered after acid-washing for samples heat-treated in argon or in argon followed by ammonia. The fact that both samples show a marked decrease in their ORR activities after acid-washing suggests a change in the relative abundance of various species, which will be discussed later.

\subsubsection{Effect of Acid Washing on the Distribution of Fe Species $\left({ }^{57} \mathrm{Fe}\right.$ Mössbauer Spectroscopy)}

To study the nature of iron species in these catalysts both before and after acid-washing, ${ }^{57} \mathrm{Fe}$ Mössbauer spectroscopy experiments were performed. Comparison of deconvoluted Mössbauer spectra for BP-Ph-Fe-Ar-NH and $\mathrm{BP}-\mathrm{Ph}-\mathrm{Fe}-\mathrm{Ar}-\mathrm{NH}_{3}$-washed samples shown in Fig. 14suggests that acid-washing does not change the phases of iron present, in agreement with XAS results. Presence of six iron species was noted as before for both samples (Table 8). The singlet at $-0.05 \mathrm{~mm} / \mathrm{s}$ was ascribed to superparamagnetic iron [15, 62, 63, 65-68]. This was also confirmed by Superconducting Quantum Interference Device (SQUID) magnetometry experiments, as discussed in the next section. Furthermore, superparamagnetic iron is encased in the carbon layers and is thereby protected as acid-washing did not decrease its intensity as noted in Table $8[15,62,65]$. Two doublets corresponding to $\mathrm{FeN}_{4}$ species with different spin states of iron [18, 62, $63,65-67,69]$ were again observed and the doublet associated with iron in +2 oxidation state and low spin state was again a dominant one. It was also noted that the intensity of the two sextets corresponding to $33 \mathrm{~T}$ and $21 \mathrm{~T}$ and assigned to $\mathrm{Fe}^{0}[15,21,63,67,70]$ and $\mathrm{Fe}_{3} \mathrm{C}$ species $[15,21,66,70,71]$, respectively was significantly reduced after acid-washing, suggesting that these components were leached out in acid as also observed by Schulenburg, et al. [71]. However, the authors in that study performed longterm acid-soaking $(100 \mathrm{~h})$ so these components were totally absent after acid-washing unlike in this study where acid-washing was performed for only $1 \mathrm{~h}$. 

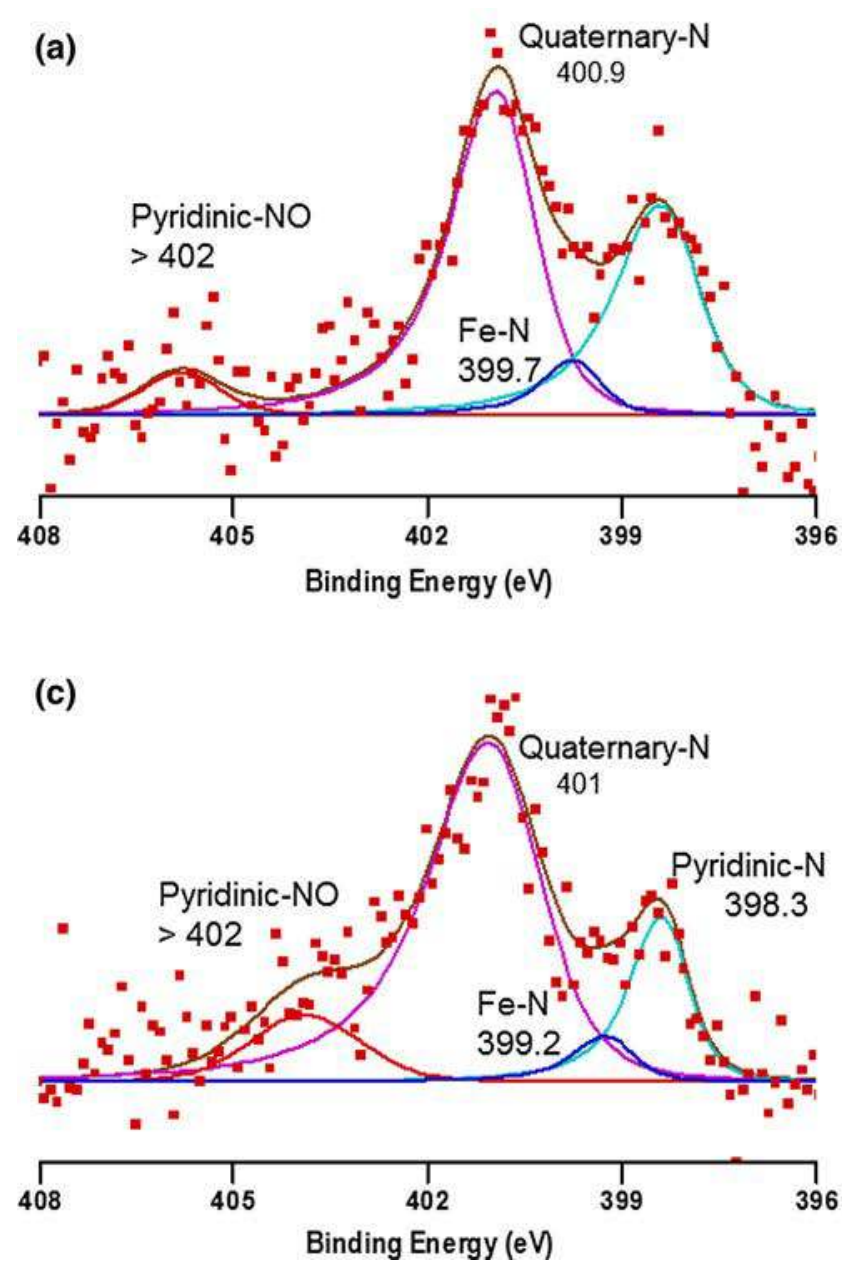
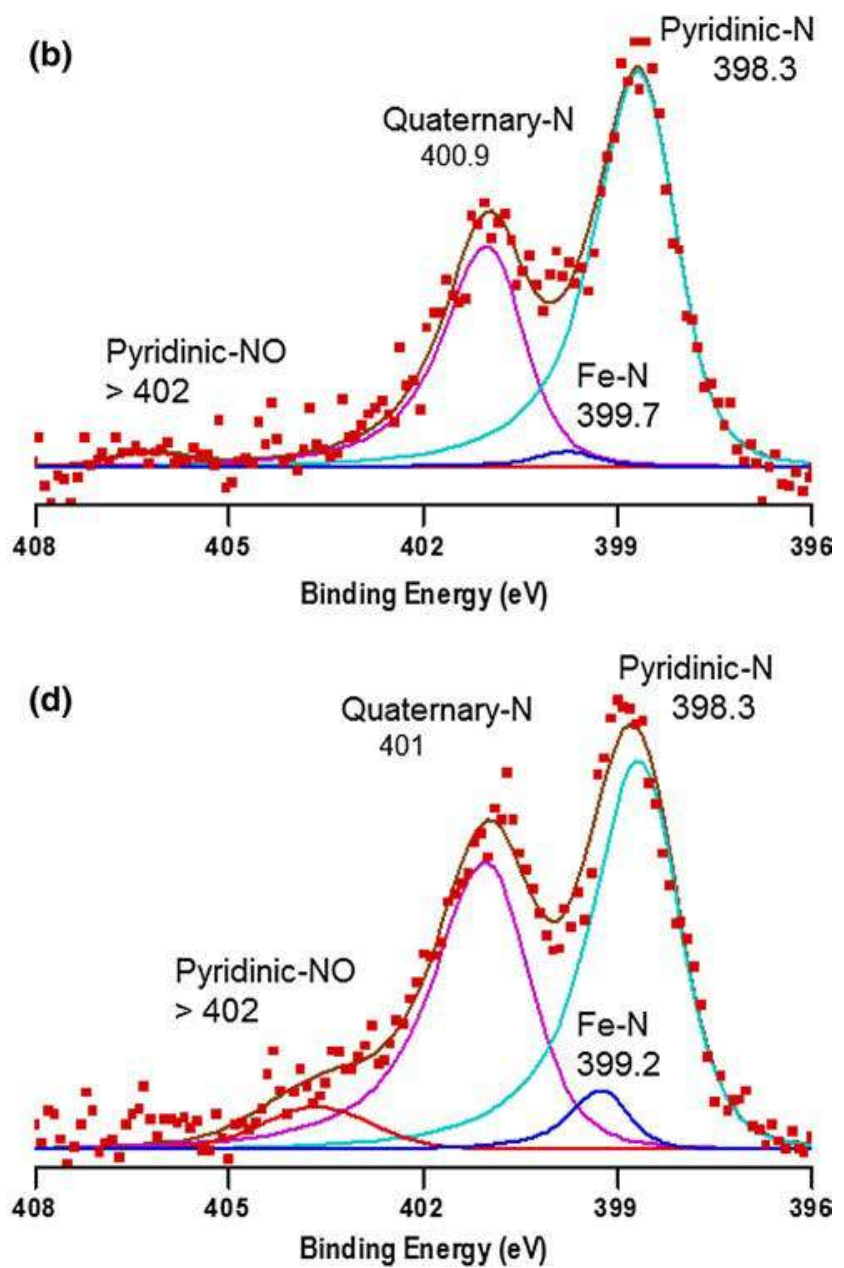

Fig. 12 N1 s XPS spectra of a BP-Ph-Fe-Ar-NH $\mathrm{NH}_{3}$, b BP-Ph-Fe-Ar-NH $-\mathrm{NH}_{3}$ washed, c BP-Ph-Fe-Ar and d BP-Ph-Fe-Ar-washed

Table 7 Effect of acid washing on the distribution of surface nitrogen species

\begin{tabular}{|c|c|c|c|c|}
\hline \multirow[t]{2}{*}{ Sample } & \multicolumn{4}{|c|}{ Relative percentage distribution (N $1 \mathrm{~s}$ ) obtained from XPS } \\
\hline & $\begin{array}{l}\text { Pyridinic-N } \\
(398.3-398.6 \mathrm{eV})\end{array}$ & $\begin{array}{l}\mathrm{Fe}-\mathrm{N} \\
(399.2-399.7 \mathrm{eV})\end{array}$ & $\begin{array}{l}\text { Quaternary } \\
(400.9-401.0 \mathrm{eV})\end{array}$ & $\begin{array}{l}\text { Pyridinic- } \mathrm{N}^{+} \mathrm{O}^{-} \\
(>402 \mathrm{eV})\end{array}$ \\
\hline $\mathrm{BP}-\mathrm{Ph}-\mathrm{Fe}-\mathrm{Ar}$ & 17 & 5 & 67 & 11 \\
\hline $\mathrm{BP}-\mathrm{Ph}-\mathrm{Fe}-\mathrm{Ar}-\mathrm{NH}_{3}$ & 35 & 6 & 54 & 5 \\
\hline BP-Ph-Fe-Ar-washed & 49 & 5 & 40 & 6 \\
\hline $\begin{array}{l}\mathrm{BP}-\mathrm{Ph}-\mathrm{Fe}-\mathrm{Ar} \mathrm{NH}_{3}- \\
\quad \text { washed }\end{array}$ & 62 & 2 & 34 & 2 \\
\hline
\end{tabular}

\subsubsection{Superconducting Quantum Interference Device (SQUID) Magnetometry}

SQUID magnetometry is based on Faraday's law of induction and can be used to precisely measure the magnetic moment of a sample of interest. The sample is moved in the direction of the applied field and through the superconducting detection coils inductively coupled to a linear current to voltage converter, producing a SQUID output voltage proportional to the magnetic moment of the sample. Magnetization (M) as a function of applied field (H) measurements were performed at $300 \mathrm{~K}$ to shed light into the magnetic behavior of FeNC materials and further validate findings from Mössbauer spectroscopy reported 
(a)

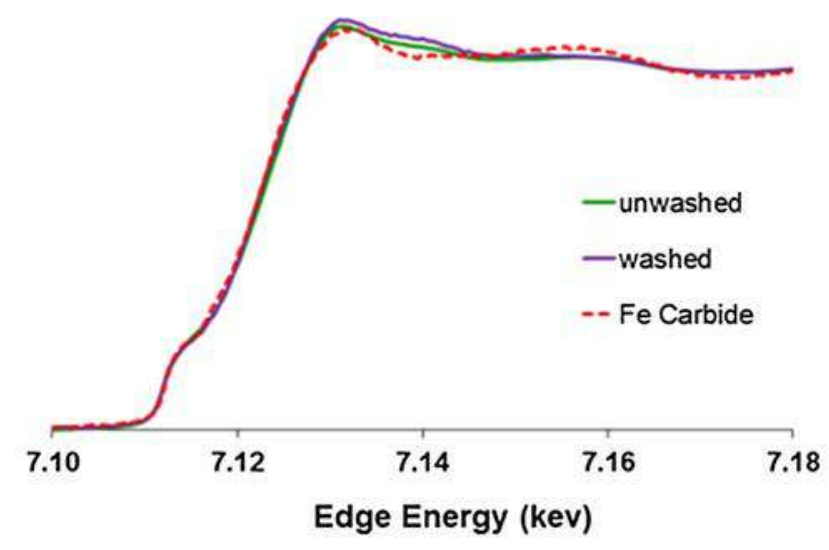

(c)

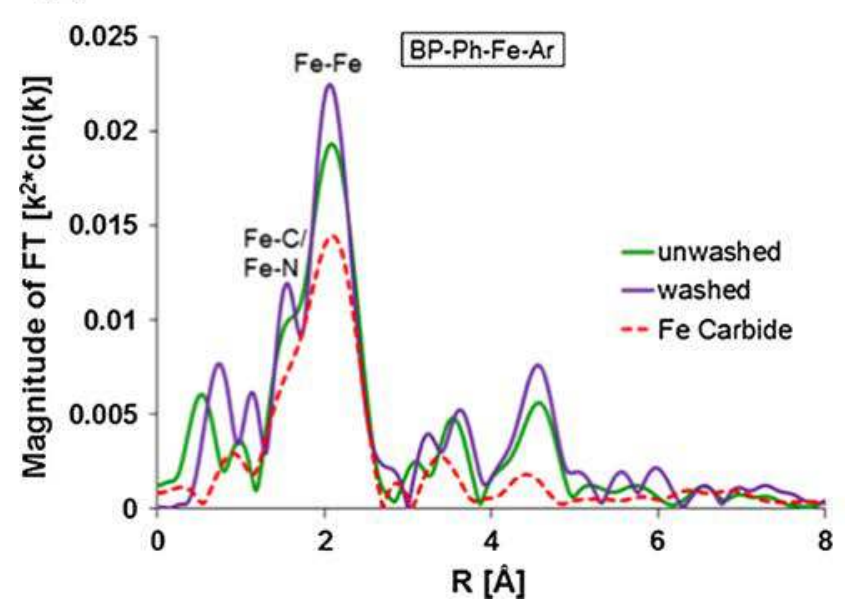

(b) $\quad$ BP-Ph-Fe-Ar-NH
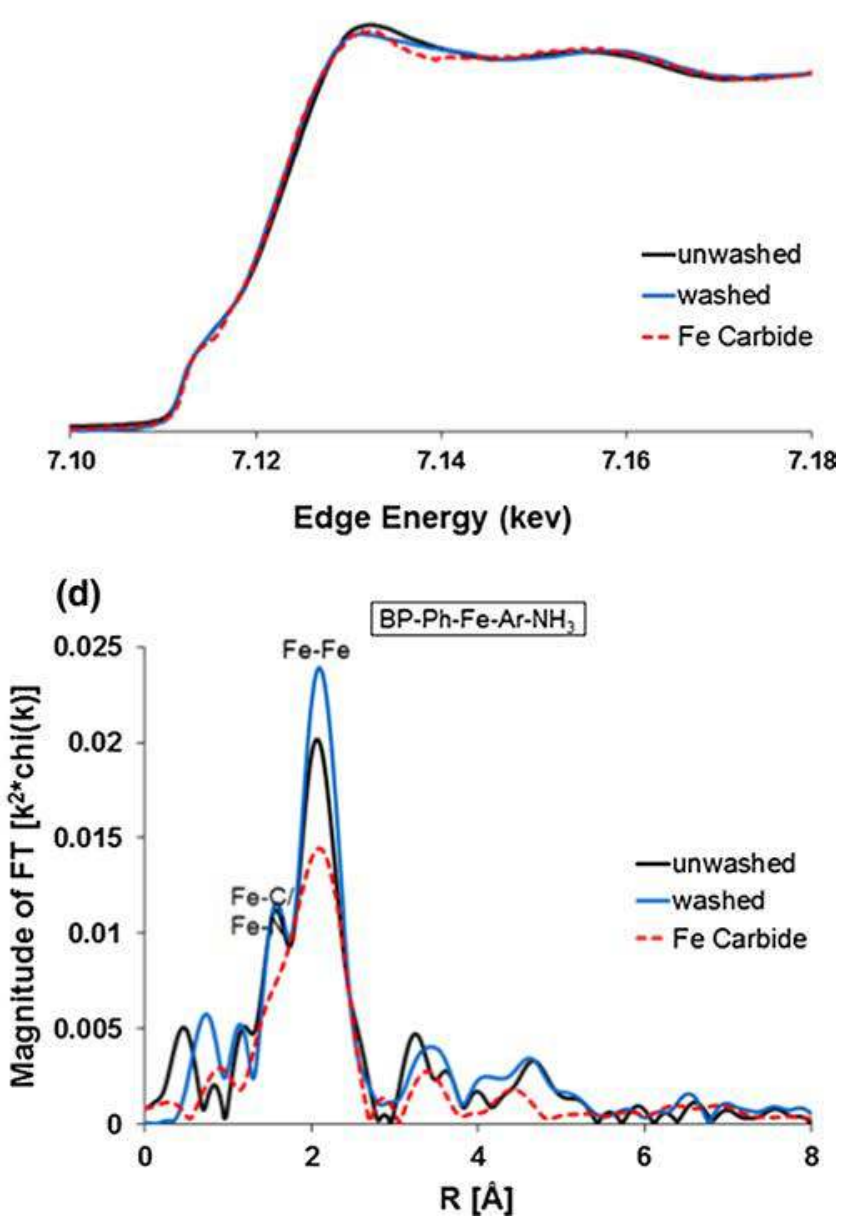

Fig. $13 \mathrm{Fe}-\mathrm{K}$ edge XAS spectra for BP-Ph-Fe-Ar and BP-Ph-Fe-Ar-NH $\mathrm{N}_{3}$ before and after acid-washing. a, b XANES, c, d EXAFS. Reference spectra for $\mathrm{FeO}$, Fe Acetate and $\mathrm{Fe}$ carbide are also included for comparison

here. Figure 15 presents the results for BP-Ph-Fe-Ar, BP$\mathrm{Ph}-\mathrm{Fe}-\mathrm{Ar}-\mathrm{NH}_{3}$ and BP-Ph-Fe-Ar- $\mathrm{NH}_{3}$-washed. All samples exhibited superparamagnetic behavior as evident from negligible hysteresis in the $\mathrm{M}$ vs. $\mathrm{H}$ curves. The saturation magnetization values obtained by fitting the collected data to Langevin function (equation ii) are shown in Table 9. It is noted that BP-Ph-Fe-Ar- $\mathrm{NH}_{3}$-washed sample has a much lower saturation magnetization value relative to its unwashed counterpart namely BP-Ph-Fe-Ar- $\mathrm{NH}_{3}$. This observation also corroborates Mössbauer spectroscopy results where it was found that the intensities of $\mathrm{Fe}^{0}$ and $\mathrm{Fe}_{3} \mathrm{C}$ phases were reduced in the washed sample.

Thus, when combined, the results obtained by using various characterization techniques such as XPS, XAS, TPO and Mössbauer spectroscopy reported here, following interesting observations can be deduced: (i) It is only the first pyrolysis in an inert that alters the iron oxidation state or the coordination environment. (ii) The nature of carbon, nitrogen and iron species are not altered by second pyrolysis in ammonia, which affects only the distribution and the abundance of various functionalities. (iii) The nature of carbon, nitrogen and iron species also remain unaltered by an acid-washing step either after first pyrolysis in argon or second pyrolysis in ammonia. However, acid-washing affects the distribution and the abundance of various functionalities.

\subsection{Site Density (SD) and Turn-Over-Frequency (TOF) Calculations}

Calculations of site density (SD) and turn-over-frequency values were performed for three most active samples in this study, namely BP-Ph-Fe-Ar, BP-Ph-Fe-Ar- $\mathrm{NH}_{3}$ and BP$\mathrm{Ph}-\mathrm{Fe}-\mathrm{Ar}-\mathrm{NH}_{3}$-washed. This analysis assumes planar $\mathrm{FeN}_{4}$ as the primary ORR active site. $\mathrm{Fe}^{2+}$ ion in low spin state coordinated to four pyrrolic nitrogen groups in a carbon matrix has been proposed as the active site for ORR in similar materials $[18,62,65]$. The site density of this site 
Fig. 14 Deconvoluted Mössbauer Spectra for a BP-Ph$\mathrm{Fe}-\mathrm{Ar}-\mathrm{NH}_{3}$ and b BP-Ph-Fe-Ar$\mathrm{NH}_{3}$-washed samples (a)

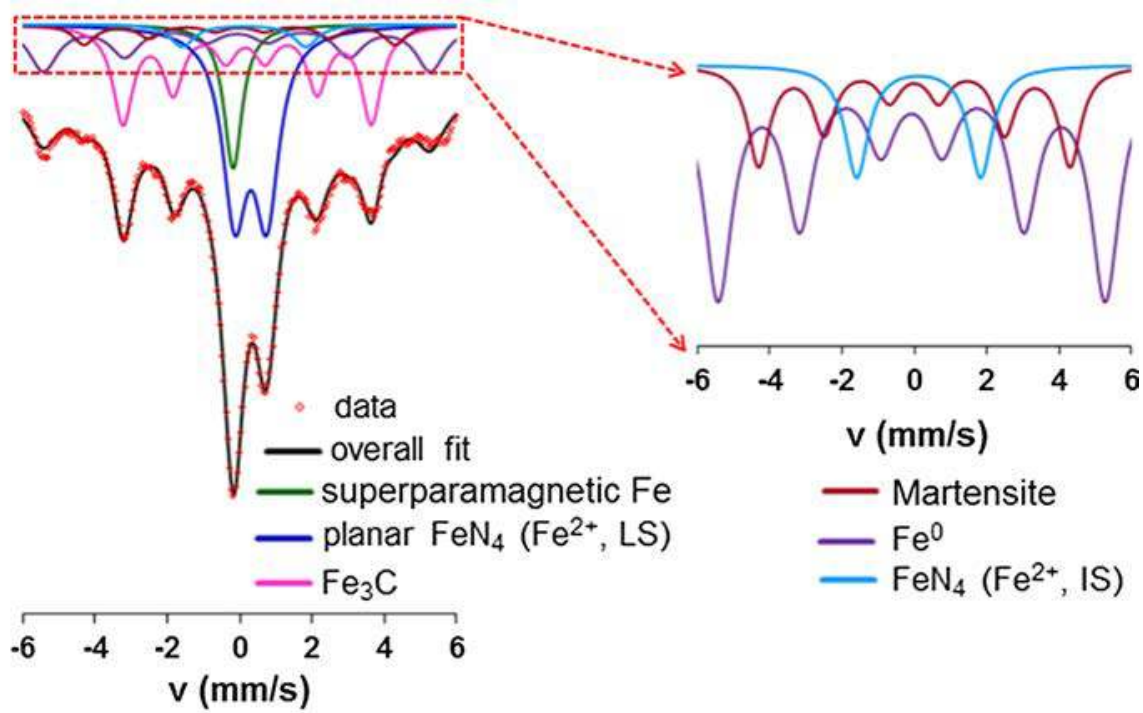

(b)

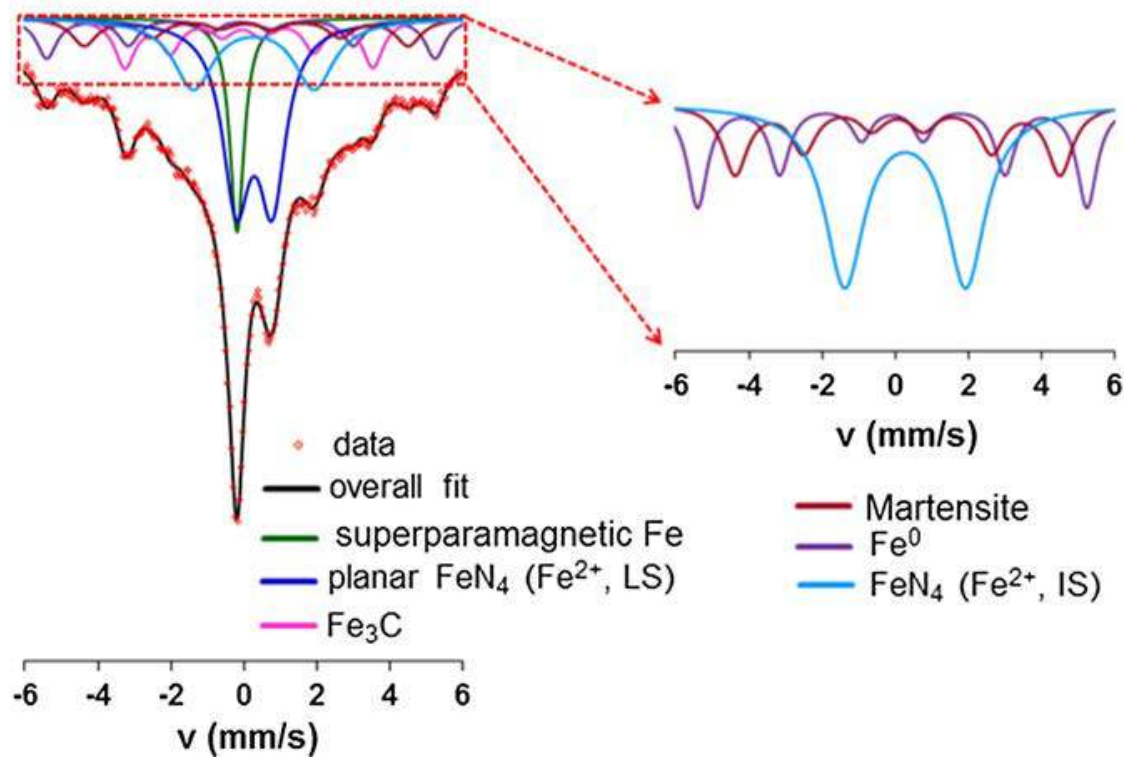

was calculated using the doublet (D1) feature in the Mossbauer spectra. Site density calculations are based on the assumption that all active sites considered in this analysis are on the surface and accessible. Another point to note is that this analysis does not include possible contributions to activity from other sites such as pyridinic-N.

The SD and TOF values obtained using the previously described methodology is presented in Table 10. The second pyrolysis treatment in ammonia is seen to enhance the site density of the planar $\mathrm{FeN}_{4}$ sites. This may be partly due to etching of the carbon support by ammonia. It may also be due to more $\mathrm{Fe}$ ions coordinating to pyrrolic- $\mathrm{N}$ groups after ammonia treatment. This observation agrees with an enhanced activity for BP-Ph-Fe-Ar- $\mathrm{NH}_{3}$ sample relative to $\mathrm{BP}-\mathrm{Ph}-\mathrm{Fe}-\mathrm{Ar}$ as noted in half-cell and fuel cell tests. The $\mathrm{SD}$ values reported here are comparable to those reported in literature for similar catalysts [62, 65]. Acid-washing leads to a decrease in the site density of the active sites. This finding supports a lower activity of the washed samples relative to their unwashed counterparts. The ICP-OES measurements confirming that part of the metal is leached out during washing were reported in our earlier publication [30].

TOF values calculated for $\mathrm{FeN}_{4}$ sites are rather similar for all samples which suggest that these values are not strongly dependent on the treatments that a particular sample has undergone (Table 10). Small variations in TOF may be due to contributions from other sites, such as $\mathrm{Fe}$ free pyridinic-N sites, which have been shown to have ORR activity in their own rights [19, 46, 49, 72].

There have also been some reports in the literature suggesting a different active site model for carbon-based 
Table 8 Effect of acid-washing on the nature of Fe species determined using Mössbauer spectroscopy

\begin{tabular}{|c|c|c|c|c|c|c|}
\hline Sample & $\begin{array}{l}\delta_{\text {iso }}(\%) \\
\mathrm{mm} / \mathrm{s}\end{array}$ & $\begin{array}{l}\Delta \mathrm{E}_{\mathrm{Q}} \\
\mathrm{mm} / \mathrm{s}\end{array}$ & $\begin{array}{l}\mathrm{H}_{0} \\
\mathrm{~T}\end{array}$ & $\begin{array}{l}\text { Rel Int } \\
\%\end{array}$ & Assignment & Reference \\
\hline \multirow[t]{6}{*}{ BP-Ph-Fe-Ar-NH ${ }_{3}$} & -0.05 & 0.00 & 0.0 & 9 & Superparamagnetic iron & {$[15,62,63,65-68]$} \\
\hline & 0.04 & 0.00 & 33.1 & 18 & $\mathrm{Fe}^{0}$ & {$[15,21,63,67,70]$} \\
\hline & 0.31 & 0.05 & 21.2 & 28 & $\mathrm{Fe}_{3} \mathrm{C}$ & {$[15,21,66,70,71]$} \\
\hline & 0.20 & 0.00 & 26.7 & 7 & Martensite & {$[64]$} \\
\hline & 0.43 & 0.89 & 0.0 & 33 & Planar $\mathrm{FeN}_{4}\left(\mathrm{Fe}^{2+}\right.$, low spin $)$ & {$[18,62,63,65-67,69]$} \\
\hline & 0.24 & 3.41 & 0.0 & 5 & $\mathrm{FeN}_{4}\left(\mathrm{Fe}^{2+}\right.$, intermediate spin $)$ & {$[18,62,63,65-67,69]$} \\
\hline \multirow[t]{6}{*}{ BP-Ph-Fe-Ar- $\mathrm{NH}_{3}$-washed } & -0.05 & 0.00 & 0.0 & 11 & Superparamagnetic iron & {$[15,62,63,65-68]$} \\
\hline & 0.04 & 0.00 & 32.8 & 12 & $\mathrm{Fe}^{0}$ & {$[15,21,63,67,70]$} \\
\hline & 0.17 & 0.15 & 21.0 & 14 & $\mathrm{Fe}_{3} \mathrm{C}$ & {$[15,21,66,70,71]$} \\
\hline & 0.18 & 0.00 & 27.4 & 9 & Martensite & {$[64]$} \\
\hline & 0.40 & 0.98 & 0.0 & 34 & Planar $\mathrm{FeN}_{4}\left(\mathrm{Fe}^{2+}\right.$, low spin $)$ & {$[18,62,63,65-67,69]$} \\
\hline & 0.39 & 3.29 & 0.0 & 20 & $\mathrm{FeN}_{4}\left(\mathrm{Fe}^{2+}\right.$, intermediate spin $)$ & {$[18,62,63,65-67,69]$} \\
\hline
\end{tabular}

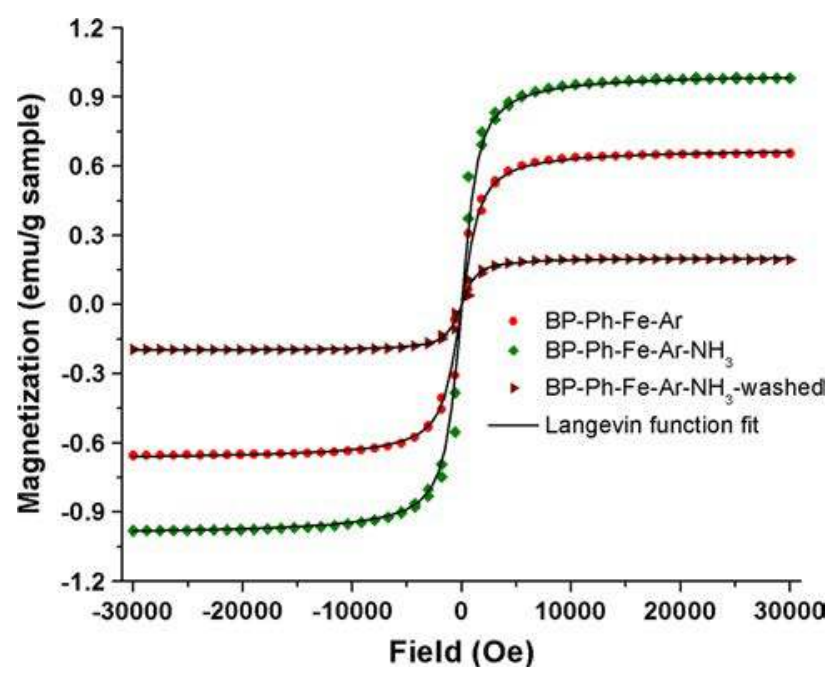

Fig. 15 Magnetization as a function of field at $300 \mathrm{~K}$

Table 9 Saturation magnetization determined by Langevin function fitting for various samples

\begin{tabular}{ll}
\hline Sample & $\mathrm{M}_{\text {sat }}(\mathrm{emu} / \mathrm{g}$ sample) \\
\hline BP-Ph-Fe-Ar & 0.7 \\
BP-Ph-Fe-Ar- $\mathrm{NH}_{3}$ & 1.0 \\
BP-Ph-Fe-Ar NH $\mathrm{N}_{3}$-washed & 0.2 \\
\hline
\end{tabular}

iron catalysts. These reports ascribe the catalytic activity to a synergistic effect between the encased $\mathrm{Fe}_{3} \mathrm{C}$ phase and the outer graphite layers [73-77]. Use of nitrogen-based precursors in the synthesis procedures employed in several of these studies raises the possibility of $\mathrm{Fe}-\mathrm{N}_{\mathrm{x}}$ and $\mathrm{CN}_{\mathrm{x}}$ type sites; however, substitution with nitrogen-free precursors for the growth of graphite layers has also shown ORR activity. For example, Hu and co-workers [78] performed experiments with a nitrogen-free precursor (durene) and noted the same trend as in the case of nitrogen-based precursor (melamine) though lower ORR activity was observed in the former relative to the latter case. In addition, the authors also observed that an acid-leaching step after employing ball-milling to expose the $\mathrm{Fe}_{3} \mathrm{C}$ phase produced a marked decrease in ORR activity [78].

We wanted to examine the possibility of this additional active site by using the Mossbauer spectroscopy, which clearly identifies the presence of $\mathrm{Fe}_{3} \mathrm{C}$ species by the sextet feature in the spectra. Using Mössbauer data for site density calculations, we assumed that both $\mathrm{FeN}_{4}$ and $\mathrm{Fe}_{3} \mathrm{C}$ sites contribute to the observed activity. It was also assumed that the intrinsic activity of a given site $\left(\mathrm{TOF}_{\mathrm{FeN} 4}\right.$ and $\mathrm{TOF}_{\mathrm{Fe} 3 \mathrm{C}}$ ) does not change from sample to sample, regardless of the treatment conditions used. In other words, it is assumed that the total electrons transferred per unit time for a particular sample is given by the summation of the products of the site density of each site with the intrinsic activity (TOF) of that site. When both $\mathrm{FeN}_{4}$ and $\mathrm{Fe}_{3} \mathrm{C}$ sites were considered, the TOF values were found to be an order of magnitude higher for the latter site, but the site density was significantly lower.

Although this is an interesting finding providing some limited support to reports for a new kind of carbon-based iron catalyst, it is not clear if the $\mathrm{Fe}_{3} \mathrm{C}$ sites identified in these $\mathrm{FeNC}$ catalysts are similar to the ones reported as being $\mathrm{Fe}_{3} \mathrm{C}$ cores encased in graphitic layers. Nevertheless, there appears to be some correlation between the overall activity and the site density of $\mathrm{Fe}_{3} \mathrm{C}$ sites. 
Table 10 Site Density (SD) and Turnover frequency (TOF) values for various catalysts

\begin{tabular}{lllll}
\hline Sample & Site & $\mathrm{SD} \times 10^{-19}($ sites/g) & TOF at $0.75 \mathrm{~V}\left(\mathrm{e}^{-} /\right.$site.s $)$ & TOF at $0.8 \mathrm{~V} *\left(\mathrm{e}^{-} /\right.$site.s $)$ \\
\hline BP-Ph-Fe-Ar & Planar FeN $_{4}$ & 4.3 & 0.17 & 0.03 \\
BP-Ph-Fe-Ar-NH & 5.8 & 0.32 & 0.05 \\
BP-Ph-Fe-Ar-NH & & 5.2 & 0.2 & 0.02 \\
\hline
\end{tabular}

* Obtained by extrapolation from TOF values at $0.75 \mathrm{~V}$

It should also be noted that presence of other type of sites such as pyridinic-N not considered here cannot be discounted. In fact, as noted in Fig. 1a, the iron-free sample namely BP-Ph- $\mathrm{Ar}-\mathrm{NH}_{3}$ also exhibits significant ORR activity.

\section{Conclusions}

The ORR performance of FeNC catalysts was studied as they evolve from their inactive precursor state to their most active form. Activity and stability measurements in halfcell and full fuel cell provided new insights into the role of $\mathrm{Fe}$ and $\mathrm{N}$ species as well as the heat treatment steps. Presence of even small amount of nitrogen in the starting synthesis mixture was seen to increase the ORR activity. Additional nitrogen incorporation using ammonia pyrolysis further enhanced the activity. Samples that contained iron and that underwent two pyrolysis steps (first in an inert, then in ammonia) were found to be most active indicating that ORR activity in FeNC materials stems from iron as well as N. Though ammonia-treated samples were more active than the ones that underwent only an inert treatment, the former were seen to lose more activity during fuel cell operation.

In addition, effect of acid washing at different stages of synthesis was examined to further probe the active sites in these materials. Acid-washing after any of the two pyrolysis steps had a detrimental effect on ORR activity indicating a metal-centered active site in these materials.

${ }^{57} \mathrm{Fe}$ Mössbauer spectroscopy was used to identify possible ORR active sites and provided insights into the deactivation behavior of these catalysts caused by acid-washing. The results suggest planar $\mathrm{FeN}_{4}$ doublet as the possible active site in these materials, which is leached away with acid-washing, explaining their decreased activity after washing. Calculations of site density and turn over frequency values for these catalysts were found to be comparable to those reported for other non-noble metal catalysts.

The ORR activities of the four most active samples were found to be linearly correlated with electrochemically accessible surface area and roughness factor computed from double layer capacitance measurements. We believe that the insights gained from this benchmarking attempt will be useful for guiding rational catalyst design as well as developing benchmarking protocols for ORR electrocatalysts.

Acknowledgments This material is based upon work supported by the U.S. Department of Energy, Office of Science, Office of Basic Energy Sciences under Award Number DE-FG02-07ER15896. We would also like to thank Ohio Coal Research Consortium or their financial support under Subcontract No. OCRC-C-04. Portions of this work were performed at the DuPont-Northwestern-Dow Collaborative Access Team (DND-CAT) located at Sector 5 of the Advanced Photon Source (APS). DND-CAT is supported by E.I. DuPont de Nemours \& Co., The Dow Chemical Company and Northwestern University. Use of the APS, an Office of Science User Facility operated for the U.S. Department of Energy (DOE) Office of Science by Argonne National Laboratory, was supported by the U.S. DOE under Contract No. DE-AC02-06CH11357.

\section{References}

1. Jasinski R (1965) J Electrochem Soc 112:526

2. Bagotzky VS, Tarasevich MR, Radyushkina KA, Levina OA, Andrusyova SI (1977) J Power Sources 2:233

3. Gupta S, Tryk D, Bae I, Aldred W, Yeager E (1989) J Appl Electrochem 19:19

4. He P, Lefevre M, Faubert G, Dodelet JP (1999) J New Mater Electrochem Syst 2:243

5. Lefevre M, Dodelet JP, Bertrand P (2002) J Phys Chem B 106:8705

6. Jaouen F, Lefevre M, Dodelet J-P, Cai M (2006) J Phys Chem B 110:5553

7. Charreteur F, Ruggeri S, Jaouen F, Dodelet JP (2008) Electrochim Acta 53:6881

8. Lefevre M, Dodelet J-P (2008) Electrochim Acta 53:8269

9. Proietti E, Dodelet JP (2008) ECS Trans 16:393

10. Proietti E, Ruggeri S, Dodelet J-P (2008) J Electrochem Soc 155:B340

11. Herranz J, Jaouen F, Dodelet J-P (2009) ECS Trans 25:117

12. Lefevre M, Proietti E, Jaouen F, Dodelet JP (2009) Science 324:71

13. Herranz J, Jaouen F, Lefevre M, Ulrike KI, Proietti E, Dodelet JP, Bogdanoff P, Fiechter S, Abs-Wurmbach I, Bertrand P, Arruda TM, Mukerjee S (2011) J Phys Chem C 115:16087

14. Proietti E, Jaouen F, Lefevre M, Larouche N, Tian J, Herranz J, Dodelet JP (2011) Nat Commun 2:416

15. Kramm UI, Lefevre M, Larouche N, Schmeisser D, Dodelet JP (2014) J Am Chem Soc 136:978

16. Larouche N, Chenitz R, Lefèvre M, Proietti E, Dodelet J-P (2014) Electrochim Acta 115:170 
17. Lefevre M, Dodelet JP, Bertrand P (2000) J Phys Chem B 104:11238

18. Kramm UI, Herranz J, Larouche N, Arruda TM, Lefevre M, Jaouen F, Bogdanoff P, Fiechter S, Abs-Wurmbach I, Mukerjee S, Dodelet JP (2012) Phys Chem Chem Phys 14:11673

19. Matter PH, Zhang L, Ozkan US (2006) J Catal 239:83

20. Matter PH, Wang E, Ozkan US (2006) J Catal 243:395

21. Matter PH, Wang E, Millet J-MM, Ozkan US (2007) J Phys Chem C 111:1444

22. Matter PH, Wang E, Arias M, Biddinger EJ, Ozkan US (2006) J Phys Chem B 110:18374

23. von Deak D, Singh D, King JC, Ozkan US (2012) Appl Catal B-Environ 113-114:126

24. Yadav RM, Wu J, Kochandra R, Ma L, Tiwary CS, Ge L, Ye G, Vajtai R, Lou J, Ajayan PM (2015) ACS Appl Mater Interfaces 7:11991

25. Wang S, Zhang L, Xia Z, Roy A, Chang DW, Baek J-B, Dai L (2012) Angew Chem Int Ed 51:4209

26. Yu D, Nagelli E, Du F, Dai L (2010) J Phys Chem Lett 1:2165

27. Qu L, Yong L, Baek J-B, Dai L (2010) ACS Nano 4:1321

28. Gong K, Du F, Xia Z, Durstock M, Dai L (2009) Science 323:760

29. Wang S, Iyyamperumal E, Roy A, Xue Y, Yu D, Dai L (2011) Angew Chem Int Ed 50:11756

30. Singh D, Tian J, Mamtani K, King J, Miller JT, Ozkan US (2014) J Catal 317:30

31. Singh D, Mamtani K, Bruening CR, Miller JT, Ozkan US (2014) ACS Catal 4:3454

32. von Deak D, Singh D, Biddinger EJ, King JC, Bayram B, Miller JT, Ozkan US (2012) J Catal 285:145

33. Jaouen F, Herranz J, Lefevre M, Dodelet J-P, Kramm UI, Herrmann I, Bogdanoff P, Maruyama J, Nagaoka T, Garsuch A, Dahn JR, Olson TS, Pylypenko S, Atanassov P, Ustinov EA (2009) ACS Appl Mater Interfaces 1:1623

34. Long D, Li W, Qiao W, Miyawaki J, Yoon S-H, Mochida I, Ling L (2011) Chem Commun 47:9429

35. Wang X, Zhou J, Fu H, Li W, Fan X, Xin G, Zheng J, Li X (2014) J Mater Chem A 2:14064

36. Li Q, Wu G, Cullen DA, More KL, Mack NH, Chung HT, Zelenay P (2014) ACS Catal 4:3193

37. Wu G, Swaidan R, Li D, Li N (2008) Electrochim Acta 53:7622

38. Braun A, Bärtsch M, Merlo O, Schnyder B, Schaffner B, Kötz R, Haas O, Wokaun A (2003) Carbon 41:759

39. Wu G, Chen Y-S, Xu B-Q (2005) Electrochem Commun 7:1237

40. Wu G, Xu B-Q (2007) J Power Sources 174:148

41. Shi H (1996) Electrochim Acta 41:1633

42. Young AP, Stumper J, Gyenge E (2009) J Electrochem Soc 156:B913

43. Liu G, Li X, Ganesan P, Popov BN (2010) Electrochim Acta 55:2853

44. Rao CV, Cabrera CR, Ishikawa Y (2010) J Phys Chem Lett $1: 2622$

45. Kundu S, Nagaiah TC, Xia W, Wang Y, Van Dommele S, Bitter JH, Santa M, Grundmeier G, Bron M, Schuhmann W, Muhler M (2009) J Phys Chem C 113:14302

46. Nallathambi V, Lee J-W, Kumaraguru SP, Wu G, Popov BN (2008) J Power Sources 183:34

47. Liu G, Li X, Ganesan P, Popov BN (2009) Appl Catal B-Environ 93:156

48. Subramanian NP, Li X, Nallathambi V, Kumaraguru SP, ColonMercado H, Wu G, Lee J-W, Popov BN (2009) J Power Sources 188:38
49. Li X, Liu G, Popov BN (2010) J Power Sources 195:6373

50. Palaniselvam T, Kannan R, Kurungot S (2011) Chem Commun 47:2910

51. Faubert G, Cote R, Guay D, Dodelet JP, Denes G, Poleunis C, Bertrand P (1998) Electrochim Acta 43:1969

52. Stanczyk K, Dziembaj R, Piwowarska Z, Witkowski S (1995) Carbon 33:1383

53. Ozaki J-i, Anahara T, Kimura N, Oya A (2006) Carbon 44:3358

54. Arechederra RL, Artyushkova K, Atanassov P, Minteer SD (2010) ACS Appl Mater Interfaces 2:3295

55. Li WM, Wu J, Higgins DC, Choi JY, Chen ZW (2012) ACS Catal 2:2761

56. Tylus U, Jia Q, Strickland K, Ramaswamy N, Serov A, Atanassov P, Mukerjee S (2014) J Phys Chem C 118:8999

57. Yang J, Liu D-J, Kariuki NN, Chen LX (2008) Chem Commun 3:329

58. Tsai C-W, Chen HM, Liu R-S, Asakura K, Zhang L, Zhang J, Lo M-Y, Peng Y-M (2011) Electrochim Acta 56:8734

59. Liu S-H, Wu J-R, Pan C-J, Hwang B-J (2014) J Power Sources 250:279

60. Bron M, Radnik J, Fieber-Erdmann M, Bogdanoff P, Fiechter S (2002) J Electroanal Chem 535:113

61. Schaaf P (1998) Hyperfine Interact 111:113

62. Kramm UI, Herrmann-Geppert I, Bogdanoff P, Fiechter S (2011) J Phys Chem C 115:23417

63. Kramm UI, Abs-Wurmbach I, Herrmann-Geppert I, Radnik J, Fiechter S, Bogdanoff P (2011) J Electrochem Soc 158:B69

64. Greenwood NN, Gibb TC (1971) Mössbauer spectroscopy, vol 1, 1st edn. Chapman and Hall Ltd, London

65. Koslowski UI, Abs-Wurmbach I, Fiechter S, Bogdanoff P (2008) J Phys Chem C 112:15356

66. Ferrandon M, Kropf AJ, Myers DJ, Artyushkova K, Kramm U, Bogdanoff P, Wu G, Johnston CM, Zelenay P (2012) J Phys Chem C 116:16001

67. Kramm UI, Abs-Wurmbach I, Fiechter S, Herrmann I, Radnik J, Bogdanoff P (2009) ECS Trans 25:93

68. Koslowski UI, Herrmann I, Bogdanoff P, Barkschat C, Fiechter S, Iwata N, Takahashi H, Nishikori H (2008) ECS Trans 13:125

69. Herrmann I, Brueser V, Fiechter S, Kersten H, Bogdanoff P (2005) J Electrochem Soc 152:A2179

70. Raupp GB, Delgass WN (1979) J Catal 58:348

71. Schulenburg H, Stankov S, Schuenemann V, Radnik J, Dorbandt I, Fiechter S, Bogdanoff P, Tributsch H (2003) J Phys Chem B 107:9034

72. Biddinger EJ, Ozkan US (2007) Top Catal 46:339

73. Wang J, Wang G, Miao S, Jiang X, Li J, Bao X (2014) Carbon 75:381

74. Li J-S, Li S-L, Tang Y-J, Han M, Dai Z-H, Bao J-C, Lan Y-Q (2015) Chem Commun 51:2710

75. Lee J-S, Park GS, Kim ST, Liu M, Cho J (2013) Angew Chem Int Ed Engl 52:1026

76. Hou Y, Huang T, Wen Z, Mao S, Cui S, Chen J (2014) Adv Energy Mater 4:1

77. Li J-S, Li S-L, Tang Y-J, Han M, Dai Z-H, Bao J-C, Lan Y-Q (2015) Chem Commun 51:2710

78. Hu Y, Jensen JO, Zhang W, Cleemann LN, Xing W, Bjerrum NJ, Li Q (2014) Angew Chem Int Ed 53:3675 